\title{
Renewable Energy Laboratory Development for Biofuels Advanced Combustion Studies
}

\section{Final Technical Report}

\author{
Dr. Valentin A. Soloiu \\ Georgia Southern University
}

\section{A. PROJECT OBJECTIVES}

The research advanced fundamental science and applied engineering for increasing the efficiency of internal combustion engines and meeting emissions regulations with biofuels. The project developed a laboratory with new experiments and allowed investigation of new fuels and their combustion and emissions. This project supports a sustainable domestic biofuels and automotive industry creating economic opportunities across the nation, reducing the dependence on foreign oil, and enhancing U.S. energy security.

\section{B. PROJECT SCOPE}

The one year period of research developed fundamental knowledge and applied technology in advanced combustion, emissions and biofuels formulation to increase vehicle's efficiency. Biofuels' combustion was investigated in a Compression Ignition Direct Injection (DI) to develop idling strategies with biofuels and an Indirect Diesel Injection (IDI) intended for auxiliary power unit.

\section{DELIVERABLES}

Purchase and Install Lab Test Equipment, Test Engine and Cluster Computer.

Train Graduate Assistants and Graduate Students to operate laboratory test equipment in order to perform Biofuels combustion and emissions test experiments.

Collect, quantify, analyze and report Biofuels test data, results and conclusions.

Final Scientific/Technical Report Submit Electronic Form DOE F 241.3 per requirements of Federal Assistance Reporting Checklist.

\section{TASKS TO BE PERFORMED}

\section{BUDGET PERIOD 1}

\section{BIOFUELS COMBUSTION AND EMISIONS INVESTIGATIONS IN DI/IDI MODE}

\section{Task A0.0 Purchasing equipment: FTIR gas analysis system, TGA-DTA instrument}

\section{a) AVL SEASAM FTIR Purchasing and Commissioning}

The System for Emission Sampling and Measurement Fourier Transform Infrared Spectroscopy or SESAM FTIR (Figure 1) is intended for measuring emissions in exhaust gases. It is a multicomponent exhaust gas measurement system that is used particularly in the development of modern engines in order to achieve compliance with the current and future exhaust gas legislation. 


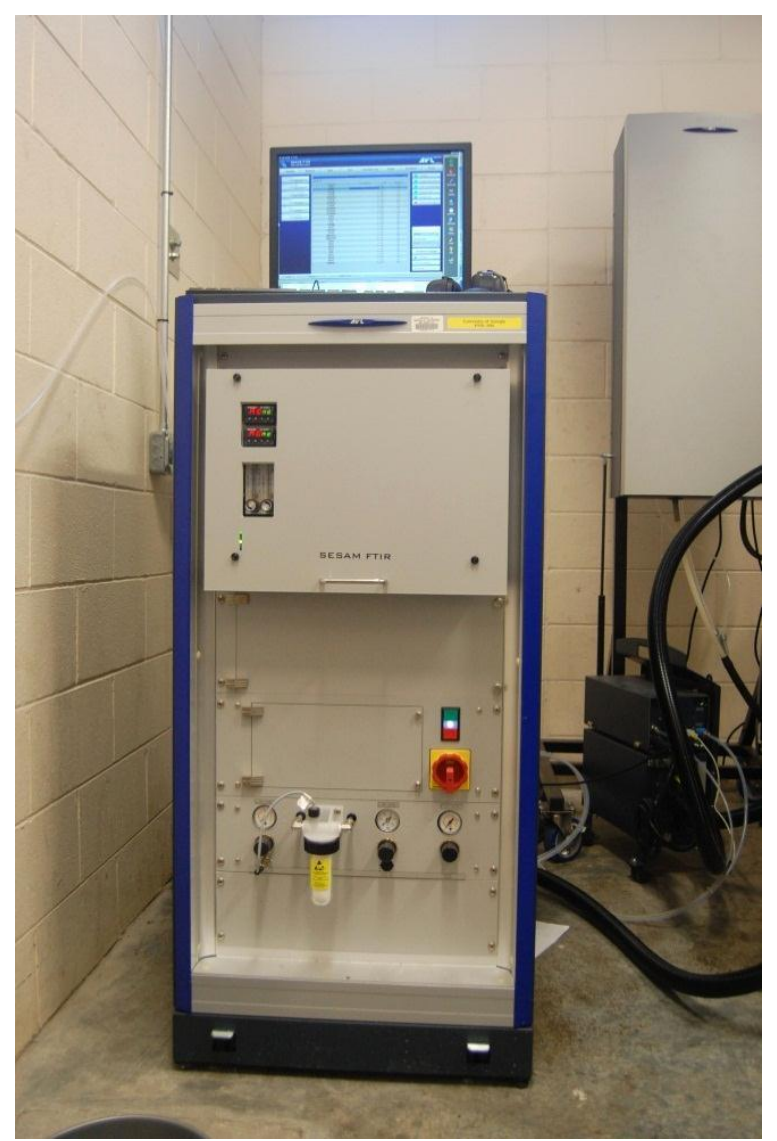

Figure 1 AVL SEASAM FTIR Main unit in GSU

FTIR is an optical measurement method that can diagnose a large number of different exhaust gas components simultaneously. By means of absorption of infrared light by the individual gas components, up to 25 gases can be measured simultaneously and synchronously. In addition, some collective components can be calculated from this process.

Table 1 Species that can be measured using the AVL SESAM FTIR

\begin{tabular}{|l|l|}
\hline \multicolumn{2}{|l|}{ Table 1 FTIR Species List } \\
\hline Carbon Dioxide $\left(\mathrm{CO}_{2}\right)$ & Benzene $\left(\mathrm{C}_{6} \mathrm{H}_{6}\right)$ \\
\hline Carbon Monoxide $(\mathrm{CO})$ & Ethyl benzene $\left(\mathrm{C}_{8} \mathrm{H}_{10}\right)$ \\
\hline Water $\left(\mathrm{H}_{2} \mathrm{O}\right)$ & Ethanol $\left(\mathrm{C}_{2} \mathrm{H}_{5} \mathrm{OH}\right)$ \\
\hline Sulfur Dioxide $\left(\mathrm{SO}_{2}\right)$ & Methanol $\left(\mathrm{CH}_{3} \mathrm{OH}\right)$ \\
\hline Nitrogen Monoxide $(\mathrm{NO})$ & Acetic Acid $\left(\mathrm{CH}_{3} \mathrm{COOH}\right)$ \\
\hline Nitrogen Dioxide $\left(\mathrm{NO}_{2}\right)$ & Acetaldehyde $\left(\mathrm{CH}_{3} \mathrm{CHO}\right)$ \\
\hline Nitrous Oxide $\left(\mathrm{N}_{2} \mathrm{O}\right)$ & Formaldehyde $(\mathrm{HCHO})$ \\
\hline Ammonia $\left(\mathrm{NH}_{3}\right)$ & Formic Acid $(\mathrm{HCOOH})$ \\
\hline Methane $\left(\mathrm{CH}_{4}\right)$ & Isocyanic Acid $(\mathrm{HNCO})$ \\
\hline Acetylene $\left(\mathrm{C}_{2} \mathrm{H}_{2}\right)$ & Hydrogen Cyanide $(\mathrm{HCN})$ \\
\hline Ethylene $\left(\mathrm{C}_{2} \mathrm{H}_{4}\right)$ &
\end{tabular}


DE-EE0003667 - Final Technical Report

\begin{tabular}{|l|l|}
\hline Ethane $\left(\mathrm{C}_{2} \mathrm{H}_{6}\right)$ & Carbonyl Sulfide $(\mathrm{COS})$ \\
\hline Cyclopropene $\left(\mathrm{C}_{3} \mathrm{H}_{6}\right)$ & $\mathrm{IC}_{5}$ \\
\hline Propane $\left(\mathrm{C}_{3} \mathrm{H}_{8}\right)$ & $\mathrm{NC}_{5}$ \\
\hline Butadine $\left(\mathrm{C}_{4} \mathrm{H}_{6}\right)$ & $\mathrm{NC}_{8}$ \\
\hline
\end{tabular}

The AVL SESAM FTIR also measures total hydrocarbon (THC) concentrations in the exhaust gas using the Flame Ionization Detector. The measuring principle is ionization of organic carbon atoms in a hydrogen flame burning in an electric field. The flame in the analyzer's burner chamber cracks and ionizes the hydrocarbons in the sample gas to very small fragments. The ions are producing a current in the electric field that is directly proportional to the number of carbon atoms in the sample. The current is electrically amplified and converted to a voltage (AVL Technical Facts).

The Infrared Detector (IRD) analyzer can be integrated for CO2 - EGR measurements. The measuring principle of the IRD is the non-dispersive infrared absorption process. This process is based on absorption at the characteristic vibration rotation spectrum bands of non-elemental gases in the middle of infrared range between 2 and $12 \mu \mathrm{m}$. Gas molecules with a bipolar moment interact with infrared radiation. The photometer consists of an infrared radiation source whose emissions reach a sample cell via a chopper wheel. The sample cell is designed as a tube that is divided into a sample and reference part. The measurement effect produced in the receiver is a pressure change effect resulting from the chopper frequency, received by a diaphragm capacitor and converted into an electrical signal by an attached preamplifier (AVL Technical Facts).

The Paramagnetic Detector (PMD) analyzer is designed for measurements of the oxygen (O2) concentration in the exhaust gas. The underlying measuring principle of the PMD is the paramagnetic property of oxygen molecules in a magnetic field. The sample gas to be analyzed is lead through a sample chamber containing a dumbbell-shaped cavity made of quartz glass that is suspended on rotary tension bands. The two cylindrical dumbbell halves are inserted into an inhomogeneous magnetic field. Oxygen molecules are drawn into the magnetic field. The produced partial pressure change applies a force to the dumbbell and generates torque to move the dumbbell from its original position. The magnitude of this torque is proportional to the oxygen concentration and can be converted into an electrical signal (AVL Technical Facts).

As part of this experiment, an exhaust manifold had to be designed and fabricated to provide adequate space for sample probe placement. The finished product can be seen in Figure 2. The custom exhaust manifold needed several provisions for sampling probes. Each of the three systems connected to the exhaust had its own requirements for probe placement. The SPC 472 sampling probe had to be the first in line, because the measurement is temperature sensitive. The second probe in the system is the AVL FTIR probe. This probe extracts the sample of exhaust gas and transfers it to the main cabinet where it is analyzed. It too is temperature sensitive, but comes equipped with a line heater to prevent any condensation build up in the line. The final probe installed into the manifold is the AVL MicroSoot sensor probe. According to the installation instructions, its placement is not crucial, just as long as the probe is facing the correct direction.

The students were intensively and comprehensively trained to use the instrument. 


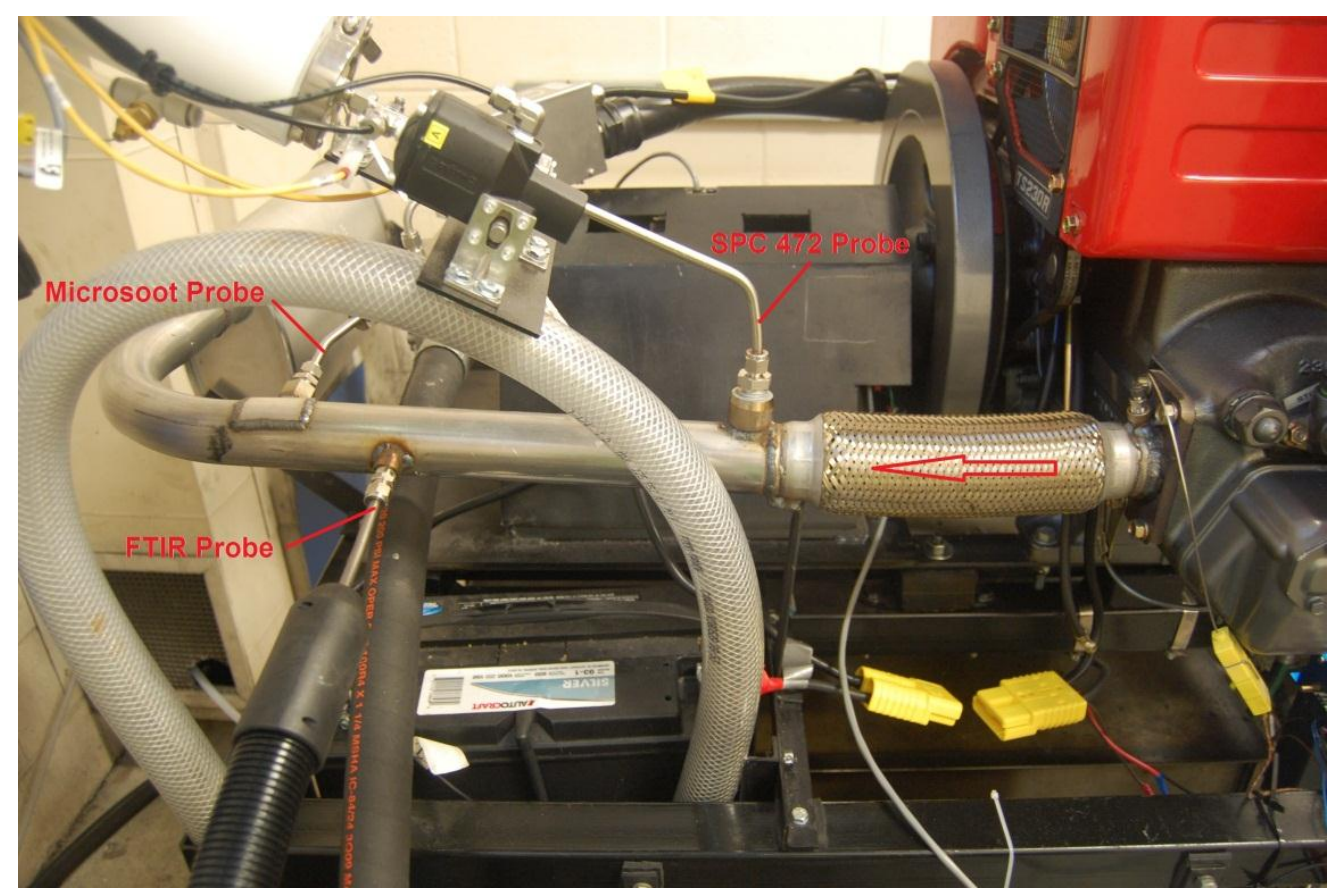

Figure 2 Sampling Probe Layout Yanmar Exhaust System

\section{b) TGA-DTA Shimadzu purchasing and commissioning}

DTG provides simultaneous differential thermal (DT) and thermogravimetric (TG) data. The TA-60WS thermal controller provides advanced acquisition, analysis, and report functions which ensure comprehensive simultaneous measurements. Installation and commissioning where straightforward operations. The students were trained to use the instrument.

Task A1.0 Investigation of the thermochemical and thermophysical properties of biofuels and their neat fatty acids and neat methyl esters

\section{Lower Heating Values of the Investigated Fuels}

The fuels investigated in this study are: ULSD\#2 as reference fuel, Peanuts FAME, and the Methyl Oleate that is the main fatty acid in the Peanuts FAME and has been chosen because it is the best candidate as reference fuel for biodiesel. The higher heating value for the tested fuels has been investigated in a calorimeter presented in Figure 3. It is seen that the LHV obtained decreases from the value reference of ULSD\#2 as the percentage of biodiesel or methyl oleate in the blend increases, Figure 4.

The GC-MS testing determined that the methyl esters of stearic, palmitic, palmitoleic, and myristic acid form the balance of the Peanuts FAEM composition. All of these methyl esters

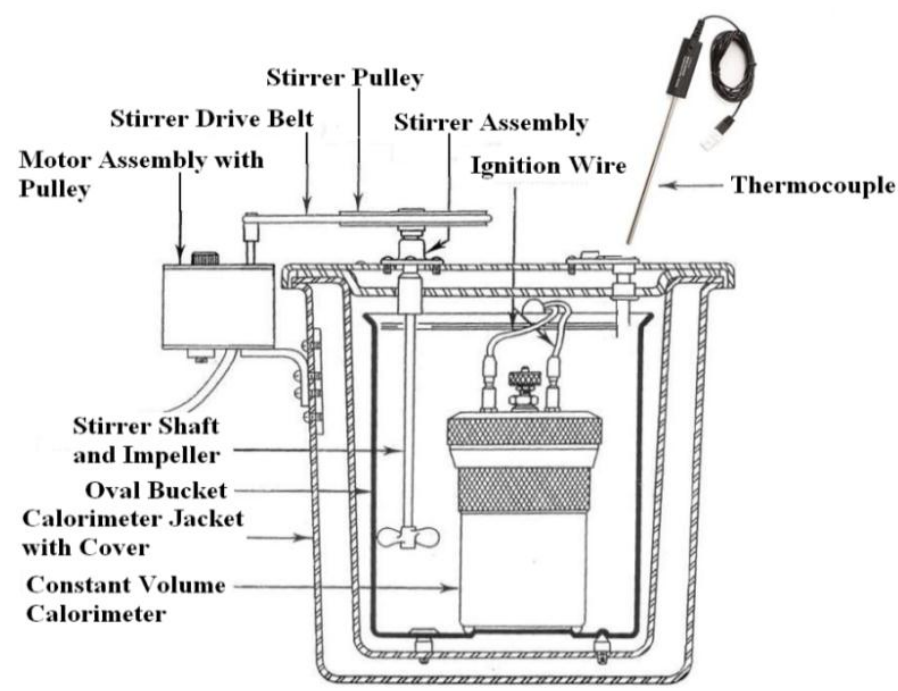

Figure 3 - Calorimeter used in the experiments 
have densities that are within 5\% that of methyl oleate, and therefore it was assumed that the methyl oleate's density would be the standard value, $0.88 \mathrm{~g} / \mathrm{cm}^{3}, \pm 2.5 \%$. The densities of the test fuels and their blends are presented in Figure 5. Table 2 displays the peanut FAME fatty acid profile.

Table 2 Peanut FAME Fatty Acids Profile

\begin{tabular}{|c|c|c|c|}
\hline $\begin{array}{c}\text { Unsaturated } \\
\text { Fatty Acids } \\
(\mathbf{U F A})\end{array}$ & $(\boldsymbol{\%})$ & $\begin{array}{c}\text { Saturated Fatty } \\
\text { Acids (SFA) }\end{array}$ & $(\boldsymbol{\%})$ \\
\hline Oleic & $58.74\left(\mathbf{X}_{\mathbf{6}}\right)$ & Palmitic & $8.78\left(\mathbf{X}_{\mathbf{3}}\right)$ \\
\hline Linolenic & 0.23 & Stearic & $2.95\left(\mathbf{X}_{\mathbf{4}}\right)$ \\
\hline Arachidic & 1.40 & Behenic & 3.22 \\
\hline Eicosenoic & 1.82 & & \\
\hline Nervonic & 1.02 & & \\
\hline Linoleic & $21.84\left(\mathbf{X}_{\mathbf{7}}\right)$ & & 14.95 \\
\hline Total (\%) of UFA & 85.05 & Total $(\%)$ of SFA & \\
\hline
\end{tabular}

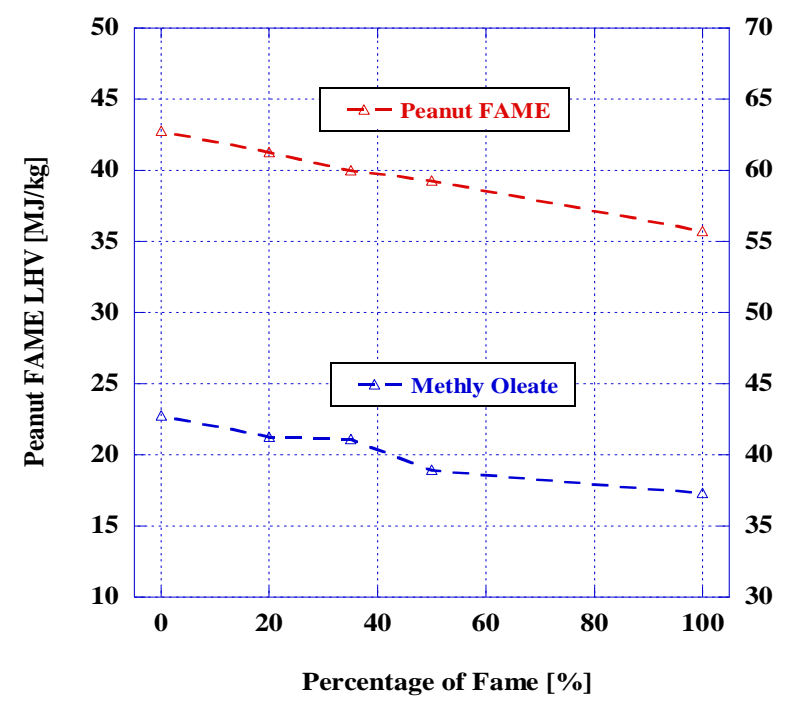

Figure 4 LHV of Peanuts FAME and Methyl Oleate

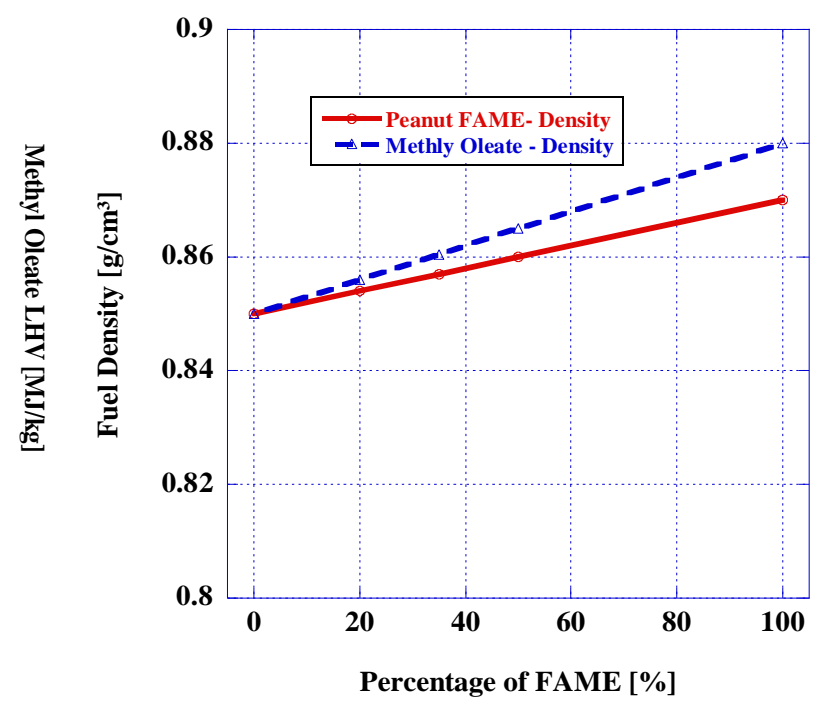

Figure 5 Densities of Peanuts FAME and Methyl Oleate

\section{Fuel Specifications}

Peanut biodiesel was produced from peanut oil using an alkali catalyst reaction with sodium hydroxide and methanol. ULSD (Diesel No. 2) was purchased from a local supplier. The properties of the peanut biodiesel are comparable to the properties of ULSD diesel in almost every aspect except cloud point, as shown in Table 3. 
Table 3 Tested fuels properties

A major advantage biodiesel has over diesel No. 2 is that it is much safer to handle due to its higher flash point. The values of viscosity, LHV, CN and cloud point were tested as a reference to the quality of the biodiesel produced and to gain insight into combustion performance. Technical grade Methyl Oleate with $78 \%$ purity was purchased from TCI America (Portland, OR). As previously stated, Methyl Oleate has been suggested in the past as a compound for enrichment in biodiesel fuels to improve biodiesel fuel properties [4]. As

\begin{tabular}{|c|c|c|c|}
\hline $\begin{array}{c}\text { Property } \\
\text { Cetane }\end{array}$ & ULSD & $\begin{array}{c}\text { Methyl } \\
\text { Oleate }\end{array}$ & $\begin{array}{c}\text { Peanut } \\
\text { FAME }\end{array}$ \\
$\begin{array}{c}\text { Number } \\
\text { Density }\end{array}$ & $0.85 \mathrm{~g} / \mathrm{cm}^{3},[4]$ & $0.88 \mathrm{~g} / \mathrm{cm}^{3},[4]$ & $0.87 \mathrm{~g} / \mathrm{cm}^{3},[3]$ \\
\hline $\begin{array}{c}\text { Viscosity } \\
@ 40^{\circ} \mathrm{C}\end{array}$ & $2.32 \mathrm{~mm}^{2} / \mathrm{s}$ & $4.27 \mathrm{~mm}^{2} / \mathrm{s}$ & $5.2 \mathrm{~mm}^{2} / \mathrm{s}$ \\
\hline LHV & $42.6 \mathrm{MJ} / \mathrm{kg},[4]$ & $37 \mathrm{MJ} / \mathrm{kg}$ & $36 \mathrm{MJ} / \mathrm{kg}$ \\
\hline MW & $233 \mathrm{~g}(\mathrm{EPA}),[4]$ & $296.5 \mathrm{~g},[4]$ & $\sim 292 \mathrm{~g},[3]$ \\
\hline $\begin{array}{c}\text { Saturation } \\
\text { Degree }\end{array}$ & $\mathrm{NA}$ & Saturated,[4] & $93,[3]$ \\
\hline Flash Pt. & $100^{\circ} \mathrm{C} \mathrm{min},[4]$ & $163^{\circ} \mathrm{C},[4]$ & $176^{\circ} \mathrm{C},[3]$ \\
\hline Cloud Pt. & $-16.1^{\circ} \mathrm{C},[4]$ & $-12.8^{\circ} \mathrm{C},[4]$ & $17^{\circ} \mathrm{C},[3]$ \\
\hline
\end{tabular}
seen from previous studies, oleic acid is definitely a suitable fatty acid for enrichment in a fatty acid profile. The melting point of $-20^{\circ} \mathrm{C}$ would suffice for most cold climate environments; however, for extreme conditions, an even lower melting point would be desired. As reported the kinematic viscosity of ULSD-O100 increases from 2.37 to $4.7 \mathrm{cP}$ at $40^{\circ} \mathrm{C}$. The oxidation stability, of less than $3 \mathrm{hr}$ (per Rancimat test at $110^{\circ} \mathrm{C}$ ), for Methyl Oleate does not the ASTM D6751-09 standards for biodiesel [9]. The oxidative stability of Methyl Oleate is considerably greater than that of the polyunsaturated esters methyl linoleate and methyl linolenate, but still requires an additive for these materials to meet the specifications in biodiesel standards.

\section{Cloud Point Evaluation}

The fuel property most important to low temperature operation of diesel engines is the cloud point, that for biodiesel is typically higher than diesel No. 2. The cloud point is the temperature at which a cloud of wax crystals first appears in a liquid upon cooling and is an indicator of the lowest operation temperature of a fuel. Operating temperatures below the cloud point for diesel fuel can result in fuel filter clogging due to the wax crystal formation.

The cloud point is determined by visually inspecting for a haze in normally clear fuel, while the fuel is cooled under carefully controlled conditions. In Figure 6, it is seen that P100 had a relatively high cloud point of $18^{\circ} \mathrm{C}$. When the sample of peanut FAME was placed in the rock salt and ice bath, the sample almost immediately turned cloudy and was completely frozen at $8^{\circ} \mathrm{C}$. As the peanut FAME was blended with diesel No. 2 it can be seen that the cloud point steadily decreases. A P20 blend (20\% peanut FAME $80 \%$ diesel No. 2) was able to reach a temperature just below $0^{\circ} \mathrm{C}$.

The high cloud point temperature of peanut FAME is influenced by the methyl stearate and palmitate composition of peanut oil, which are solid at room temperature. The peanut oil contains approximately $20 \%$ stearic and palmitic fatty acids, which are saturated esters with no double bonds leading to increased density.

The Methyl Oleate cloud point values were calculated from referenced values based of the percentage Methyl Oleate and USLD in each fuel blend. Figure 6 displays a graph of the cloud point of Peanuts FAME and Methyl Oleate blends. 


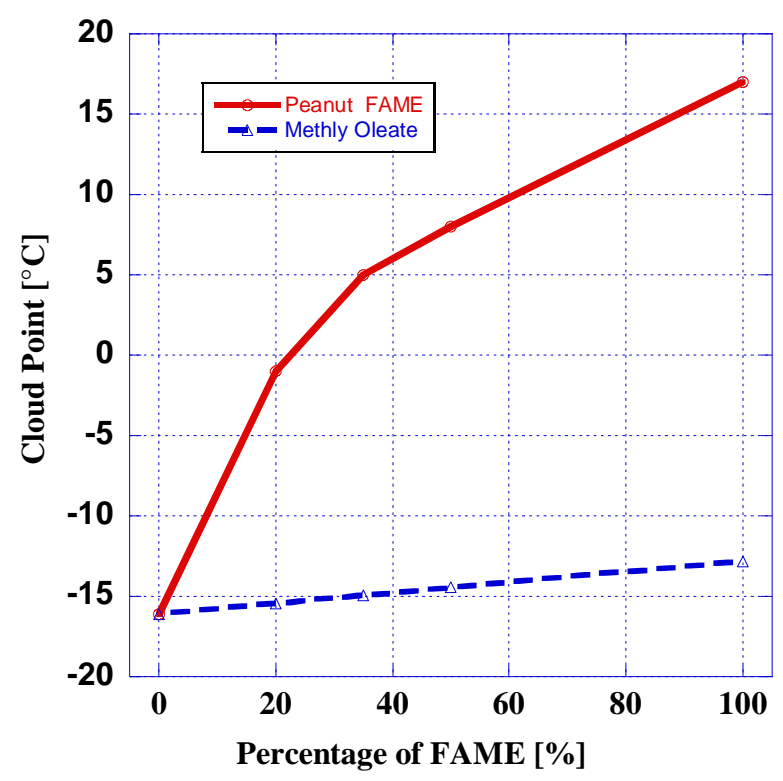

Figure - 6 Cloud point of the tested fuels

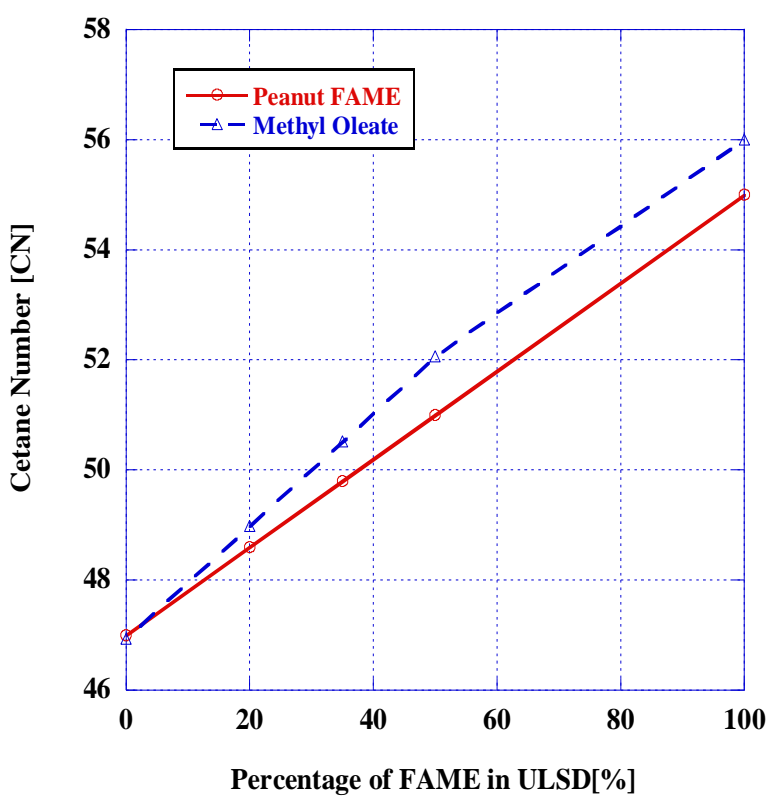

Figure 7 Cetane number for biodiesel blends

\section{Cetane Number}

Our previous works [2-4] found a CN of 47 for ULSD, and the CN for Peanut FAME was 78. Since such high value of 78 is less plausible for biodiesel a theoretical model was applied for the $\mathrm{CN}$ for the peanut FAME and Methyl Oleate also. The $\mathrm{CN}$ is determined accurately by using a regression model based on fatty acid composition percentage, proposed by Bamgboye and Hansen [1].

From these values, the cetane numbers for different blends were calculated based on the percentage of each fuel type based on Table 2 . The regression equation used was as follows:

$$
C N=61.1+0.088 x_{2}+0.133 x_{3}+0.152 x_{4}-0.101 x_{5}-0.039 x_{6}-0.243 x_{7}-0.395 x_{8}
$$

The variables $\mathrm{x}_{2}, \mathrm{x}_{3}, \mathrm{x}_{4}, \mathrm{x}_{5}, \mathrm{x}_{6}, \mathrm{x}_{7}$ and $\mathrm{x}_{8}$ represent the percentage of fatty acid methyl esters, and the coefficients for the saturated FAMEs are positive and increase with an increase in the carbon number. The coefficients of the unsaturated FAMEs are negative because they showed a reduction in the overall cetane number with unsaturation [1]. Based on this model and fatty acids percentage in Table 2, the cetane numbers for peanut FAME and Methyl Oleate were obtained to be 55 and 56 respectively. Figure 7 displays the results of the cetane numbers obtained from the discussed model. 


\section{Thermo Gravimetric Analysis}

The thermo gravimetric and differential thermal analysis were conducted in order to investigate the vaporization and oxidation properties of the fuels in question. The results demonstrated that up to a temperature of approximately $200^{\circ} \mathrm{C}$, the peanut FAME is deemed stable, with a minimal amount of vaporization occurring, in comparison to ULSD from which lighter fractions were already starting to release at approximately $75^{\circ} \mathrm{C}$. The vaporization speed is higher for FAME as seen as seen in Figure 9. Methly oleate, shown in Figure 10 , began to vaporize at about $80^{\circ} \mathrm{C}$. The peanut FAME endothermic reaction takes place in the range from 200 to $320^{\circ} \mathrm{C}$ and the Methly Oleate blends of B20 and B50 show the same trend with up to $350^{\circ} \mathrm{C}$, while for diesel is about $325^{\circ} \mathrm{C}$. The exothermic reaction of the peanut FAME and methly oleate is longer than for the diesel, Figure 8, 10. This is attributed to the multiple components that comprise the peanut FAME and the fact that the methly oleate contained $10 \%$ of other FAME components as seen in Figure 11. The largest fraction of peanut FAME, Methly Oleate and ULSD is oxidized between 450 and $500^{\circ} \mathrm{C}$.
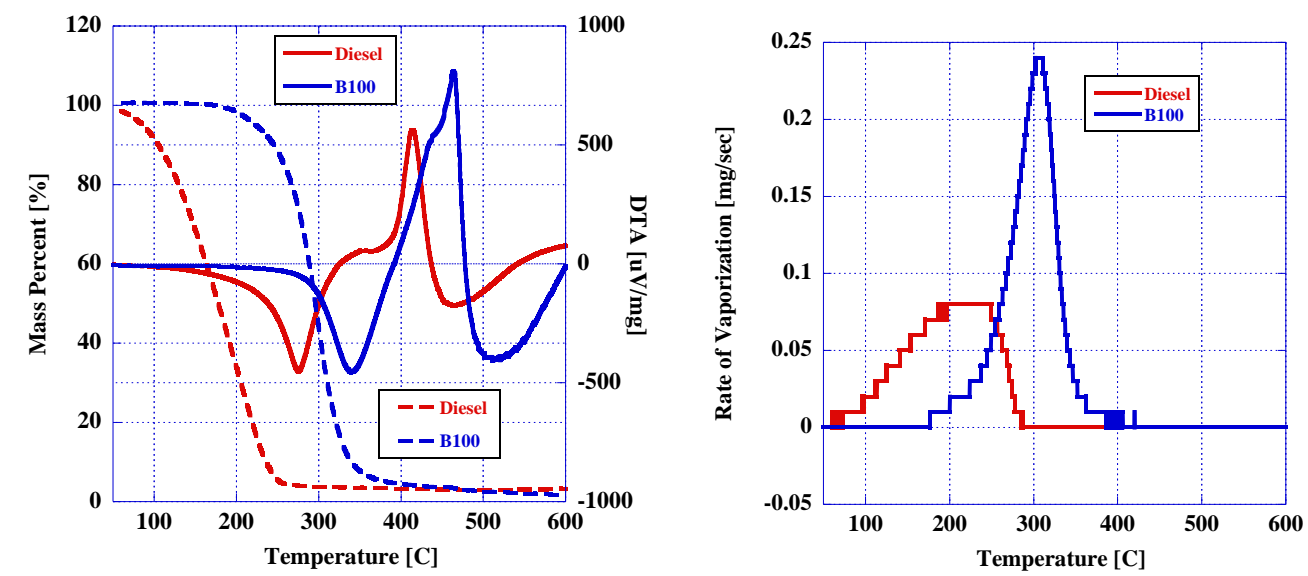

Figure 8 Comparison TGA-DTA Peanuts FAME Figure 9 Vaporization rate of Peanuts FAME vs ULSD\#2 versus ULSD\#2

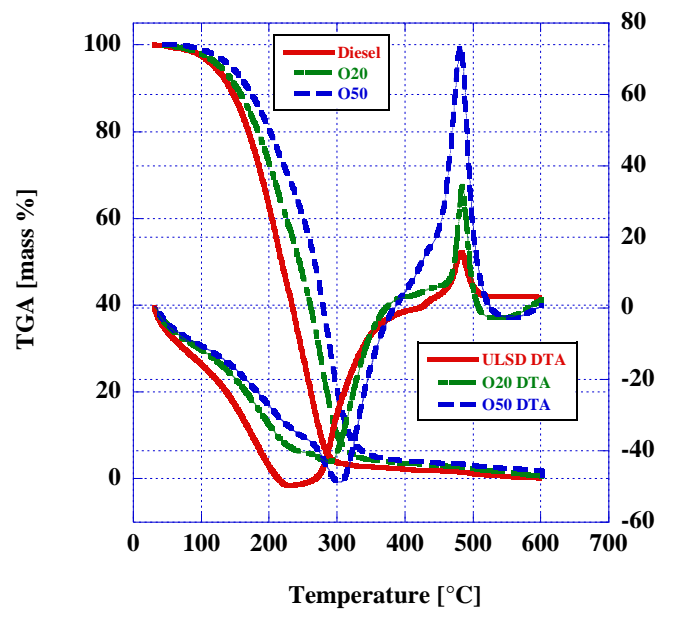

Figure 10 TGA-DTA Methyl Oleate vs USLD\#2

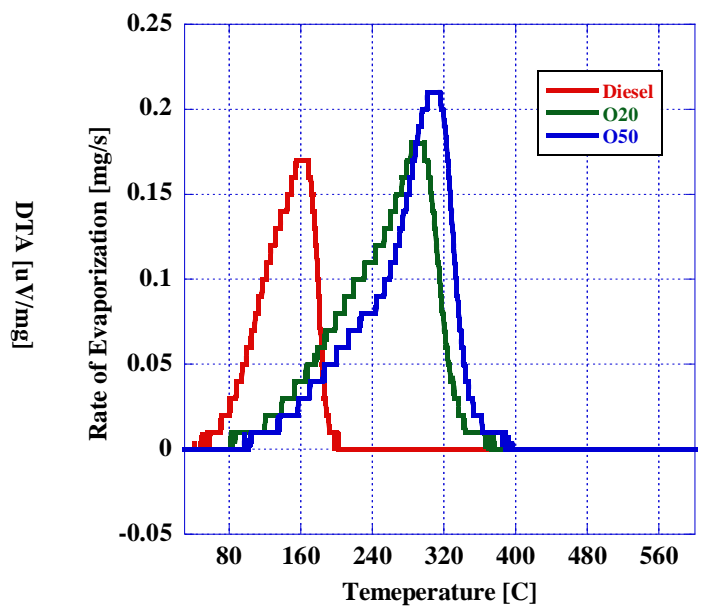

Figure 11 vaporization rate for Methyl Oleate blends vs ULSD\#2

\section{Dynamic viscosity}


One of the most important properties of biodiesel is that of viscosity, due to its pronounced effect on the operation of the fuel injection system. This effect is particularly prominent at low temperatures at which the increase in viscosity can lead to inadequate spray atomization and injector clogging. The poor atomization can lead also to increased carbon deposits causing increased wear to develop, which significantly impacts performance negatively with respect to mechanical efficiency and power output. However, the higher viscosity range of biodiesel has some positive benefits, reducing barrel/plunger leakage and increasing injector efficiency.

From the previous research [2-4], it was found that the viscosity of biodiesel is slightly higher than that of diesel, but of less magnitude than the original crude bio-oil used for production. For all the fuel mixtures in the viscosity studies, (0-100\% peanut FAME), the viscosity was investigated at various temperatures to determine changes with respect to temperature and percentage of FAME in USLD\#2. Test comparisons were done with a Brookfield Viscometer DV II Pro type. Fitted with the Small Sample Adapter attachment the instrument selection came from the conditions that the viscometer had to handle low viscosity liquids, ease of maintenance, and resistant to contamination. The viscosity study of the test fuels, took place at various viscometer temperatures ranging from $26^{\circ}-60^{\circ} \mathrm{C}$, verifying that the viscosity of the test fuels and diesel blends are slightly higher than that of diesel alone, and depending on the biodiesel content. The diesel engines require a fuel viscosity between 1-10 cP and the fuels' viscosity is essential since it influences droplet size, penetration, and mixing rate with the air, vaporization, emissions, smoke, and wall deposits; as a result, engine efficiency and emissions characteristics are determined. The data collected, and displayed in Figure 12, showed that at $40^{\circ} \mathrm{C}$ the viscosity of USLD\#2 up to P100 (peanuts) ranged from 2.3-5.2 cP. The results show that the viscosity increases with higher content of FAME in the mixtures and as the temperature increases, the viscosity decreases sharply. These results determined that the peanut FAME/USLD\#2 mixtures were within the ASTM viscosity standard when using up to 50\% FAME. Methyl Oleate's viscosity is lower than that of Peanuts FAME by about $25 \%$ as seen in Figure 13 giving good atomization prospects.

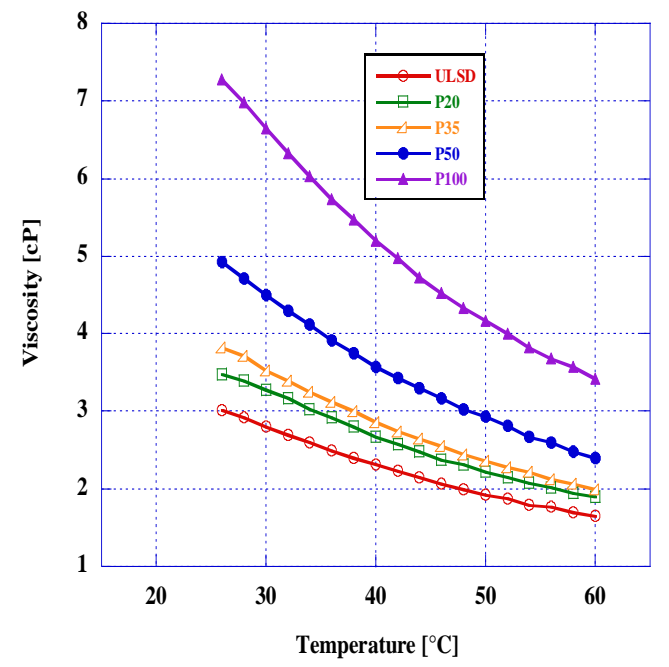

Fig. 12 Peanuts FAME viscosity vs temperature

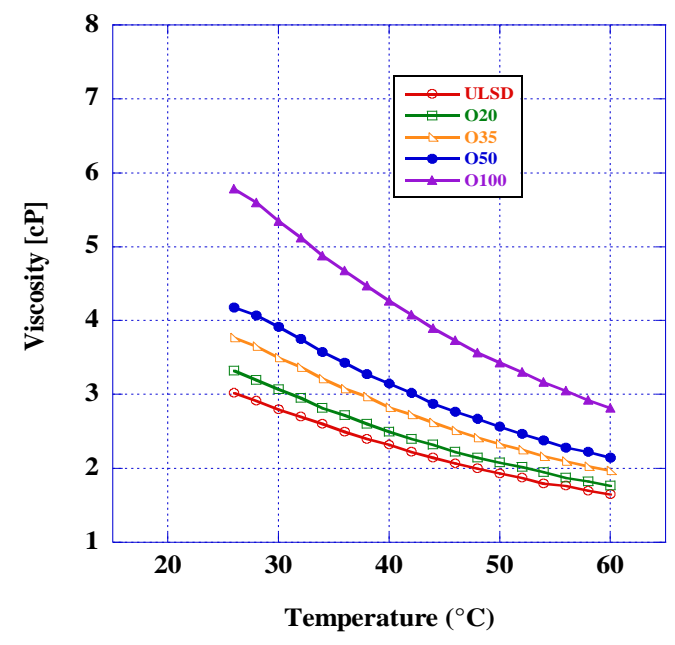

Fig. 13 Viscosity vs. Temperature for Methyl Oleate 


\section{Task A2.0 Combustion analysis of biofuels and their fatty acid methyl esters}

Experiments were carried out in an omnivorous (multi-fuel) naturally aspirated, water-cooled, $1.13 \mathrm{~L}$, single cylinder, direct injection engine and an IDI single cylinder engine with $0.35 \mathrm{~L} /$ cyl. Specifications of the DI engine are in Table 4 and for IDI engine in Table 5. Each engine was coupled to a hydraulic dynamometer.

Table 4 DI single cylinder - engine Specifications

\begin{tabular}{|l|c|}
\hline \multicolumn{2}{|l|}{ Single cylinder, NA, 2 valves/cyl, no EGR } \\
\hline Maximum Power & $16.9 \mathrm{~kW}$ \\
\hline Maximum Torque & $77.47 \mathrm{~N} \bullet \mathrm{m}$ \\
\hline Bore $\times$ Stroke & $112 \mathrm{~mm} \times 115 \mathrm{~mm}$ \\
\hline Displacement & $1132 \mathrm{cc}$ \\
\hline Injection nozzle & $200 \mathrm{bar}$ \\
\hline Injection Pressure & $20 \mathrm{BTDC}$ \\
\hline Injection timing & $16: 1$ \\
\hline Compression Ratio & \\
\hline
\end{tabular}

The DI engine was four-stroke, liquid cooled and naturally aspirated with two valves per cylinder and the experiments were performed without the use of EGR at this stage of research. The engine parameters given in Table 4, were used in the thermodynamics calculations presented throughout this paper; the experimental set-up is presented in Figure 14. Soot emissions were measured from the exhaust line using an AVL 383 Micro Soot Sensor at dilution ratio of 1:9. Gaseous emissions were measured using an AVL SESAM FTIR V4 (25 species).

Air flow into the engine was measured using a computerized Meriam Laminar Flow Meter, the in-cylinder pressure was determined using a Kistler 6053cc uncooled piezoelectric pressure sensor, and the injection pressure was measured using a Kistler 6533A11 in-line injection pressure sensor. An Omron optical encoder was used to measure the crank angle for data acquisition at $50 \mathrm{KHz}$, that is at every 0.1 CAD at $800 \mathrm{rpm}$ representing $0.02 \mathrm{~ms}$, by using an Yokogawa 750 DL high speed data acquisition system. Experiments were carried out at an engine speed of $800 \mathrm{rpm}$, representing low speeds and low to medium loads for the experimental engine to investigate idling strategies. The engine was allowed to run until exhaust gas temperature, cooling water temperature and lubrication oil temperature became steady. Measurements were taken at engine loads ranging from 1 to 3 bars indicating mean effective pressure and a static injection timing of 20 CAD BTDC. 


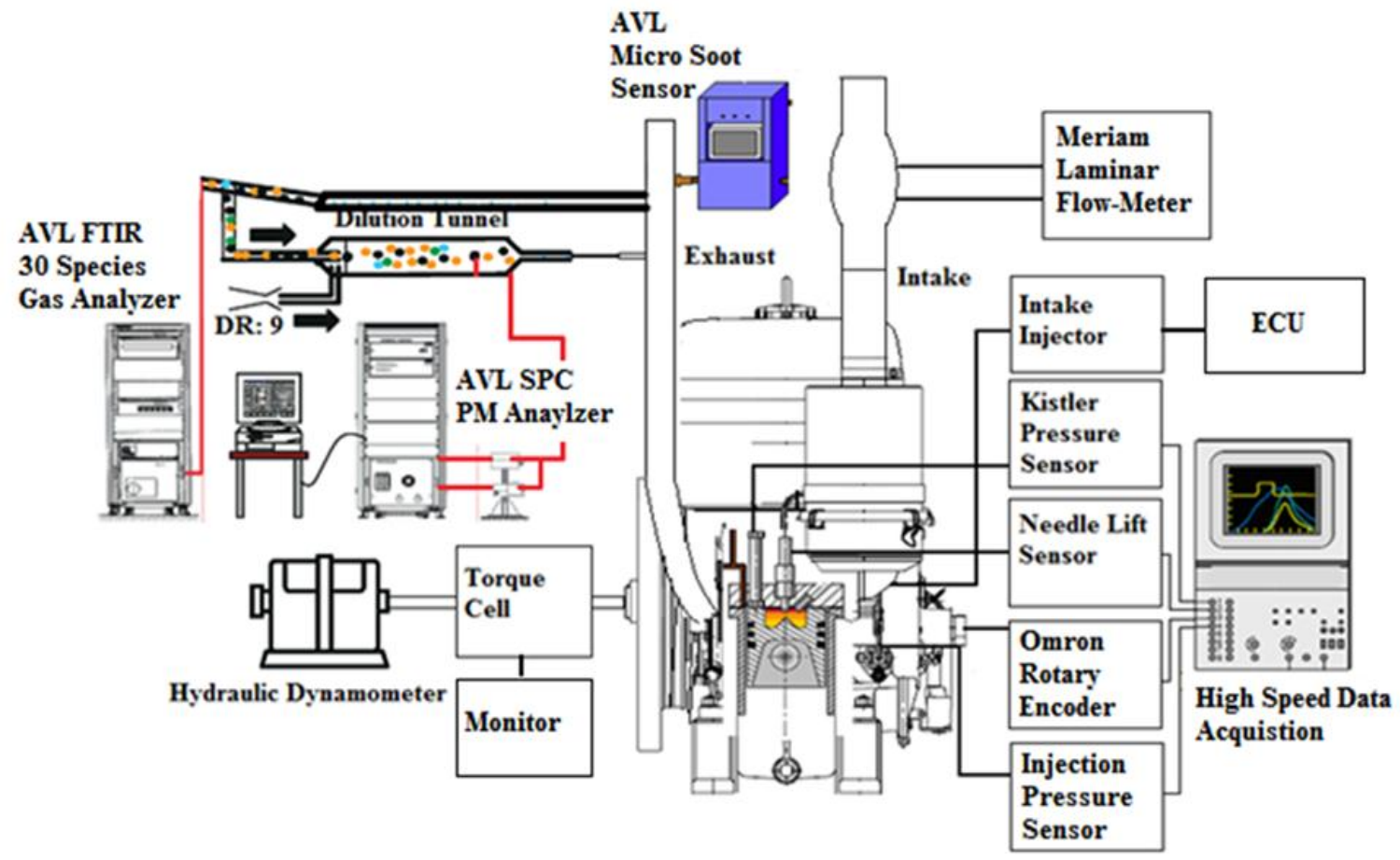

Figure 14 Direct Injection Engine experimental set-up

\section{The Indirect Injection Engine}

Recently interest has increased in the research of indirect injection engines for use with alternative fuels $[2,6]$. This type of engine has been investigated for Auxiliary Power Units applications for civil and miltary operation $[3,4]$ due in part to the fact that it is more tolerant for use with alternative fuels, as a consequence of the fuel being introduced in a very hot high swirl chamber. This allows for lower injection pressure since the swirl chamber produces a very turbulent flow leading to fast evaporation and mixing. After the ignition, the burning mixture is pushed into the main combustion chamber, where its turbulent and rapid flow continues to mix with the remaining air and fuel. This results in swifter flame propogation and thus, a shorter combustion period.

The research was performed with a 4-stroke, indirect injection compression-ignition, single cylinder engine with a triple vortex (three orifices) combustion chamber. The engine is liquid cooled and naturally aspirated, with two valves per cylinder, and the experiments were performed without the use of EGR. The engine was controlled by a hydraulic dynamometer at $100 \%$ continuous load ( 6.2 bar imep) and $2.9 \mathrm{~kW}$ of continuous power at $2200 \mathrm{rpm}$. The engine parameters are given in Table 5, and were used in the thermodynamics calculations presented throughout this paper. Cylinder pressure was measured with an uncooled piezoelectric high pressure sensor (Kistler) introduced through the glow plug, with the sensor output signal conditioned by a charge amplifier (Kistler). Data acquisition was performed with a high speed data acquisition system (Yokogawa), at $50 \mathrm{kHz}$, synchronized to the engine crankshaft position by the use of a rotary encoder with 2000 pulse/rev resolution (Omron). Air flow rates were measured with a computerized laminar flow element (Meriam). The experimental set-up for the IDI engine is described in Figure 15. 


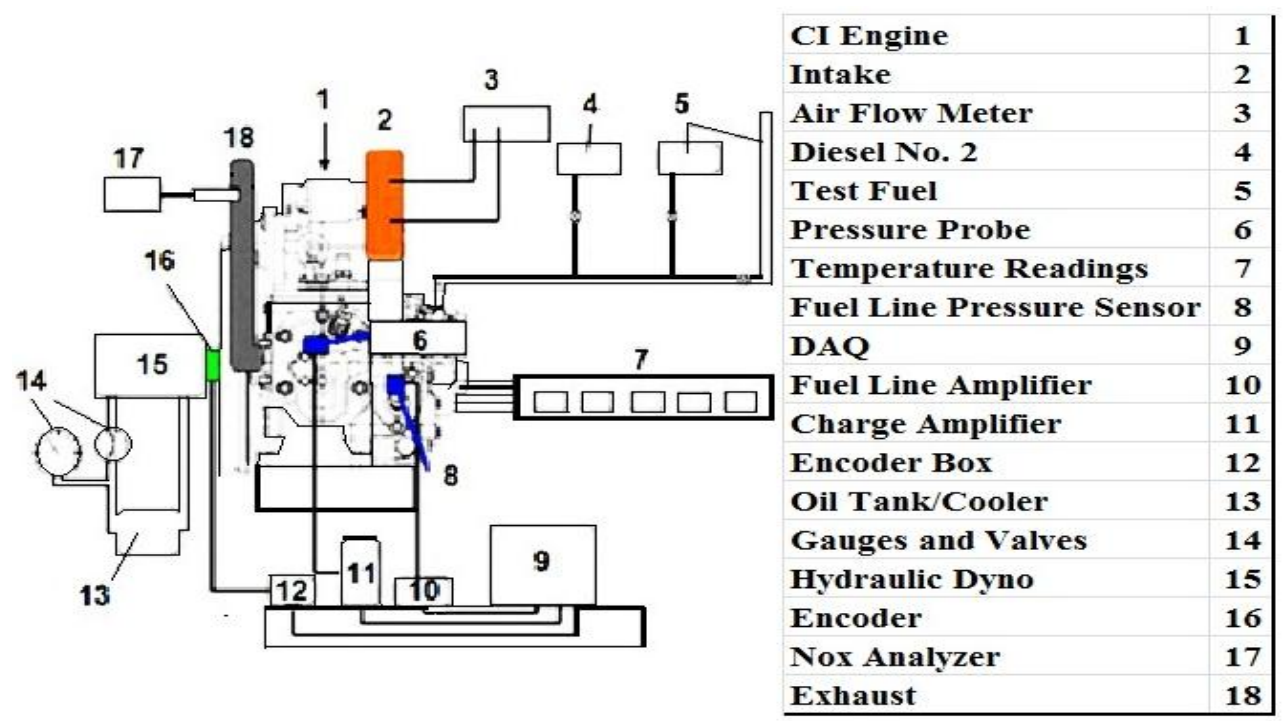

Figure 15 The research set-up for the IDI engine

Table 5 IDI Engine Specifications

\begin{tabular}{|l|c|c|c|}
\hline Parameter & Symbol & Unit & Value \\
\hline Displacement & $\mathrm{Vs}$ & Liters & 0.35 \\
\hline Compression Ratio & $\varepsilon$ & $\mathrm{N} / \mathrm{A}$ & $23.5: 1$ \\
\hline Bore x Stroke & $\mathrm{D} \mathrm{x} \mathrm{S}$ & $\begin{array}{c}\mathrm{mm} \mathrm{m} \\
\mathrm{mm}\end{array}$ & $77 \times 70$ \\
\hline Number of Cylinders & $\mathrm{i}$ & $\mathrm{N} / \mathrm{A}$ & 1 \\
\hline Number of Strokes & $\tau$ & $\mathrm{N} / \mathrm{A}$ & 4 \\
\hline Engine Effective Power & $\mathrm{P}_{\mathrm{e}}$ & $\mathrm{kW}$ & 2.9 \\
\hline
\end{tabular}

\section{RESULTS}

\section{Biofuel injection event study by injector needle lift sensor and high pressure injection line sensor for DI engine}

A needle lift sensor set-up was designed and introduced in the injector of the DI engine. The needle lift sensor determines the displacement of the needle in the injector during fuel injection. Each fuel used in the engine has its own distinct viscosity value which may affect injection (needle displacement in the injector) and injection timing with impact on ignition delay. In order to calibrate the needle lift sensor, it was placed in a perpendicular position with respect to a flat plate on top of the needle valve in the injector. The gap was recorded as the sensor was moved back and forth at equal increments of $0.1 \mathrm{~mm}$ and the signal emitted in relation to the sensor displacement was determined on the oscilloscope, Figure 16. The data from the oscilloscope was used to determine the relationship between voltage emitted by the sensor and its displacement obtaining a calibration curve. It was found that between 0.6-1.0 mm the relation between gap and signal is linear and the sensor was set at $0.75 \mathrm{~mm}$. The Figure 17 shows the voltage emitted as it is related to needle lift sensor displacement and Figure 18 the signal in the engine from which it was found the injection timing is 20 CAD BTDC. 


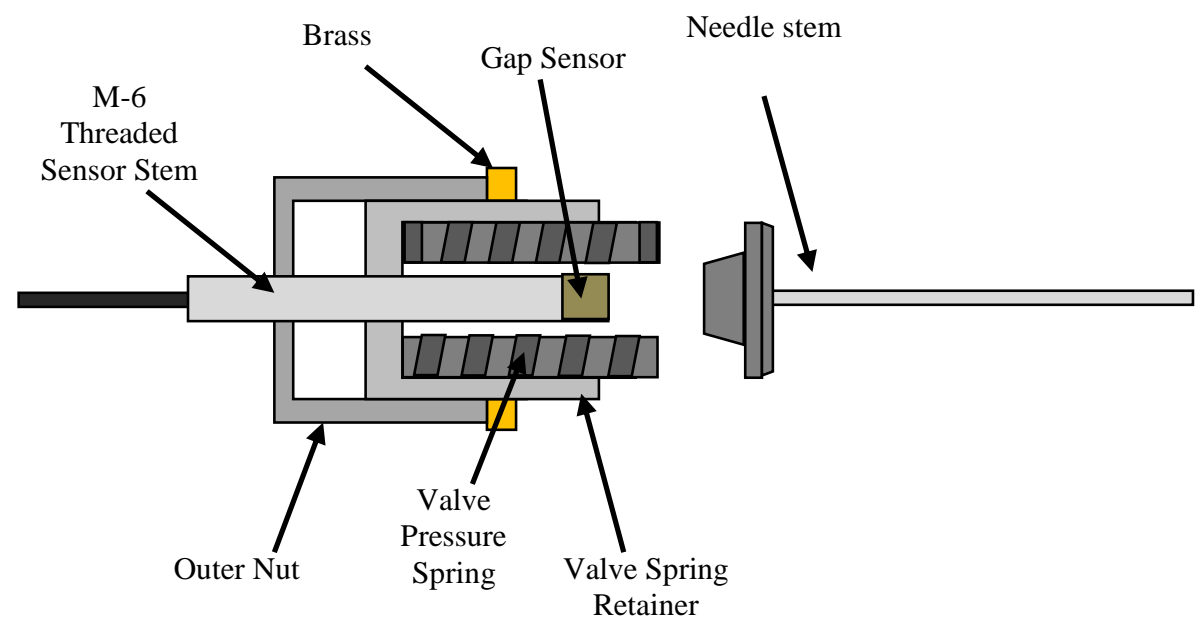

Figure 16 Needle lift set up in the DI engine injector

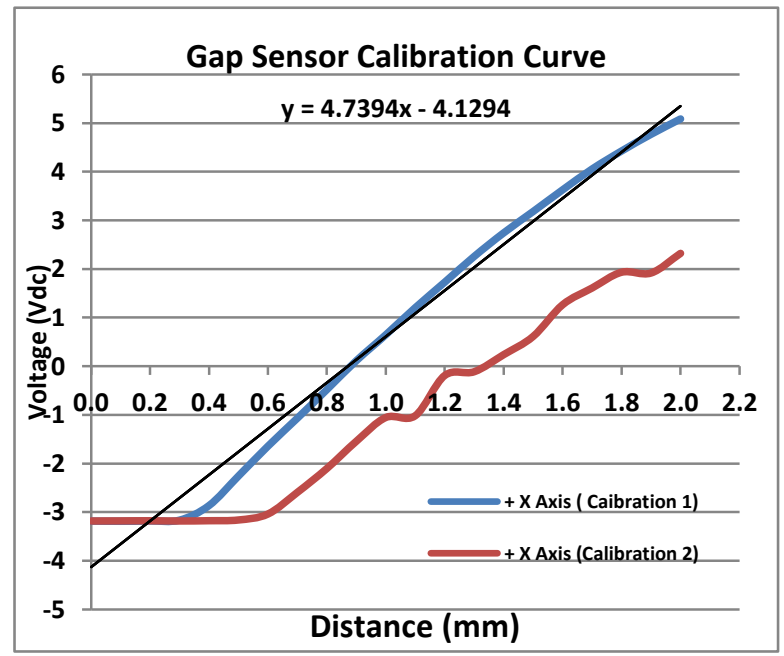

Figure 17 Calibration curve for the needle lift sensor

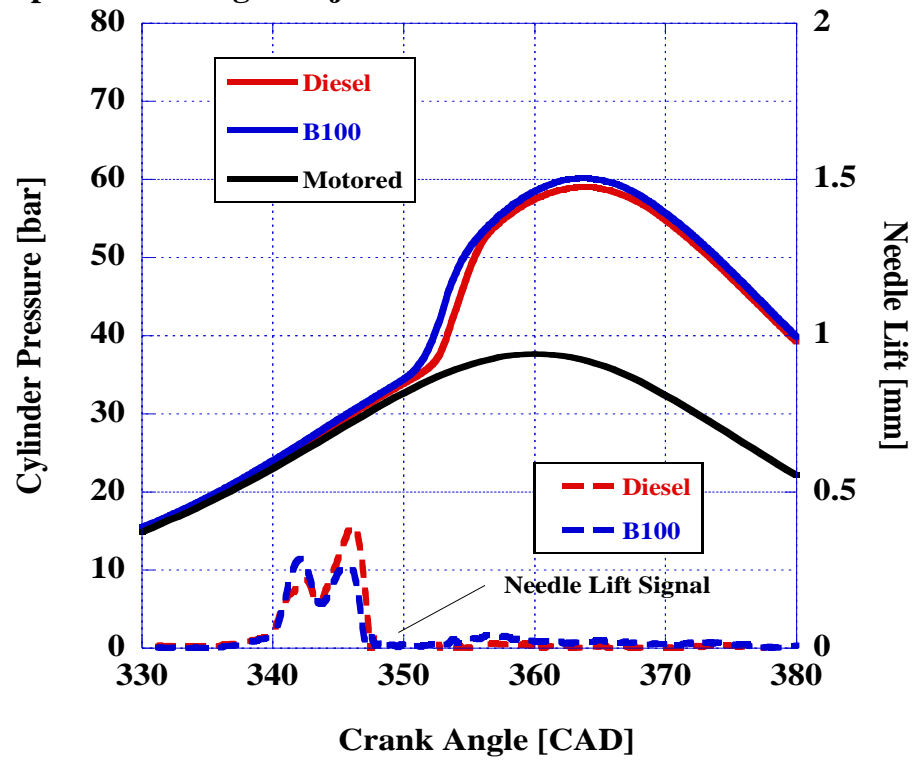

Figure 18 Needle lift signal in the DI engine

\section{IDI engine}

The experimental indicated cylinder pressure diagrams for the IDI engine are presented in figure 19 showing the baseline ULSD reference cycles compared with peanut FAME, and in Figure 20 Methyl Oleate blends at $100 \%$ continuous load $(6.2$ bar imep) and $2200 \mathrm{rpm}$. Based on the data, it can be concluded that the type of biofuel blend introduced into the system has a minimal effect, with the maximum combustion pressure remaining relatively constant for all fuel blends up to B50 for both the peanut FAME and methyl oleate blends. The maximum combustion pressure at $2200 \mathrm{rpm}$ and $100 \%$ load (6.2 bar imep) was 72, 73 and 74 bar for ULSD, peanut FAME (P50), and methyl oleate (O50), respectively.

The experimental results for the fuel line pressures, presented in Figures 19 and 20, do not display any symptoms of the fuel line injector opening prematurely when using FAME and the mechanical injection system associated with this experiment using peanut FAME with 147 bar injection pressure displayed no modification in injection timing throughout the investigation. The engine was stable and 
able to run relatively smoothly using the peanut FAME-diesel and methyl oleate blends with no injection or ignition difficulties observed.
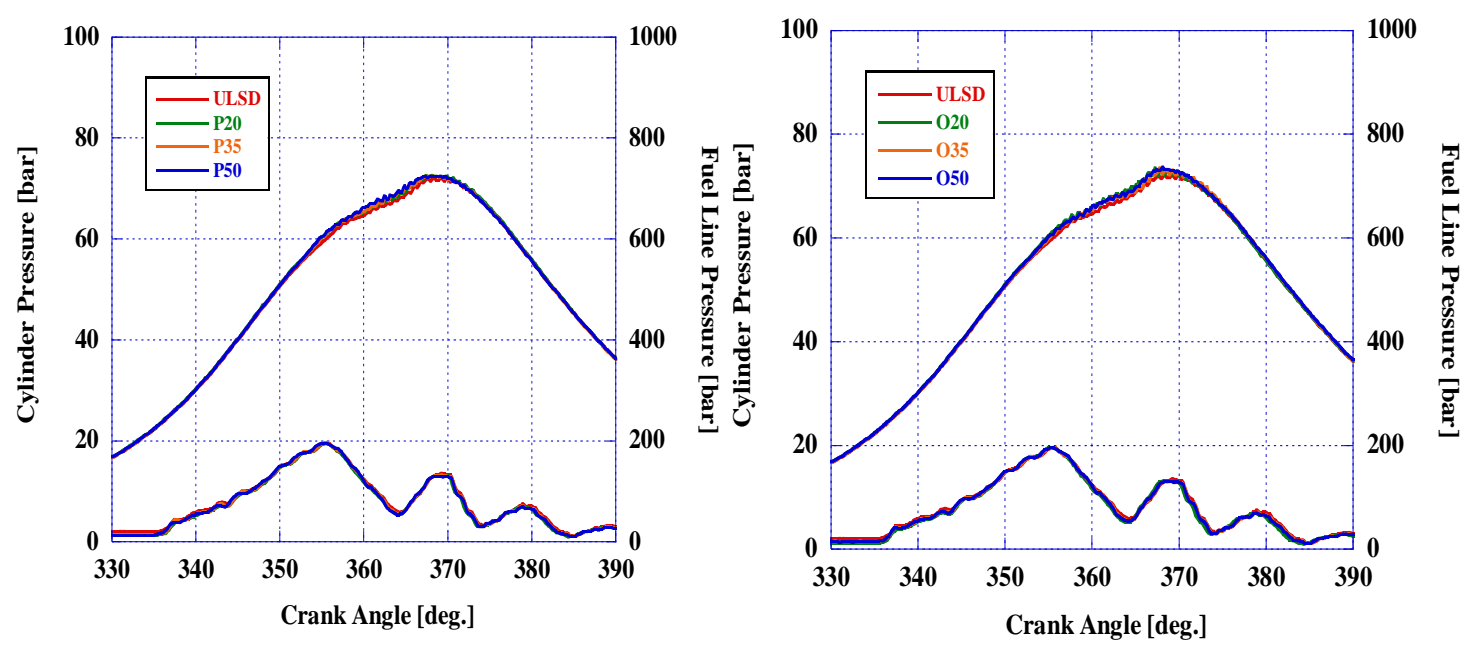

Figure 19 Peanuts FAME vs ULSD\#2 in cylinder Figure 20 methyl Oleate vs ULSD\#2 in cylinder and injection pressures and injection pressures

\section{The Investigation of Hydraulic Delay Impact on Injection Timing}

The fuel's bulk modulus, density, and viscosity can vary the needle lift and injection duration in a hydraulic plunger-barrel injection system. A higher bulk modulus can cause a steeper rise in fuel pressure at the start of injection and cause the injector needle to open earlier [2]. The influence of component fatty acid properties on injection timing and injection duration compared with diesel fuel may be attributed to differences in bulk modulus between the fuels. These are believed to result from differences in structure and intermolecular forces that dictate the free space between molecules [3]. Aromatic compounds were found to be less compressible than their saturated counterparts, while long-chain paraffins are the most compressible of the hydrocarbons. In addition to hydrocarbon structure, the presence of oxygen also influences biodiesel fuel's compressibility. It creates a permanent dipole moment that causes oxygenated molecules to exhibit stronger hydrogen bonding and increased molecular affinity compared to pure hydrocarbon molecules. These factors reduce the free space between molecules in biodiesel, decreasing its compressibility (high bulk modulus) relative to diesel fuel [4]. The injection timing modification has been investigated experimentally and the interest comes from its influence on ignition delay and combustion.

In a previous study from Tat et al [7], it was determined that there was a 0.68 CAD injection timing advance of biodiesel compared with diesel No. 2 due to property changes for a pump-line-nozzle injection system. An advance in injection timing is believed to contribute to an increase in NOx emissions and a different engine performance than the original settings chosen by the engine manufacturer.

Equation 2 displays a derived formula for calculating the crank angle required to reach nozzle opening pressure (NOP), where the rate of volume change produced by the injection pump or unit injector is set equal to the rate of fuel compression. Equation 3 displays final formula used to calculate the crank angle required to reach nozzle opening pressure, where Po is the initial system pressure, $\mathrm{V}_{f}$ is the volume of compressed fuel, $\beta$ is the bulk modulus of elasticity, $V_{\alpha}$ is the volume of the plunger, and $A_{p}$ is the cross sectional area of the plunger. This formula was used to analyze the injection timing for ULSD, peanut FAME, and methyl oleate.

$$
V_{\alpha} A_{p}=\frac{V_{f}}{\beta} \times \frac{d P}{d \alpha}
$$




$$
\alpha=\frac{(N O P-P o) V f}{\beta V_{\alpha} A_{p}}
$$

Figure 21 displays the calculated advance in injection timing in crank angles with respect to the percentage of FAME in the biodiesel mixtures. The results demonstrate for the IDI engine a very slight advance in injection timing for Peanut FAME and methyl oleate when compared with ULSD, with Peanut FAME having a greater deviation than its main fatty acid component. Tat and Gerpen [7] stated that this trend correlates well with the increase in NOx observed from Peanut FAME. However, the advance in this case is not significant enough to affect engine performance. The displayed injection timing advances are all under 0.1 degrees, which correlates well with the fuel-line pressure crank angle position overlays displayed in Figures 19 and 20.

\section{Apparent Heat Release Rate}

The Apparent Heat Release Rate (AHRR) was calculated from the cylinder pressure data, sampled at

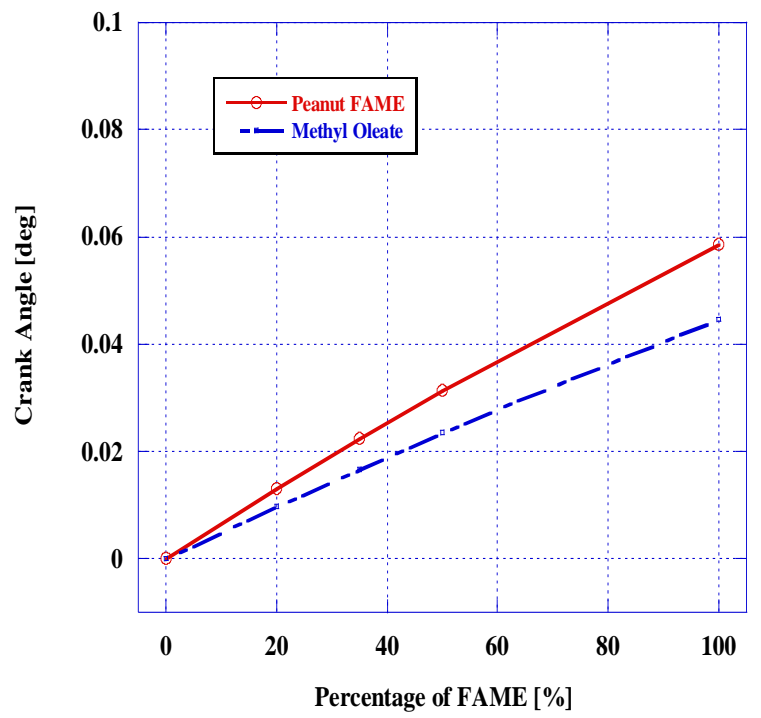

Figure 21 Hydraulic injection delay for various blends of FAME

a resolution of 0.18 crank-angle degrees $(0.01 \mathrm{~ms})$. Implied in this analysis are the assumptions of constant mass (neglected mass changes due to fuel injection, crevice flow, and blow by, a single, homogeneous volume, and ideal gas behavior. The formulation of the AHRR is given by equation 4 .

\section{Engine}

$$
\frac{d Q}{d \alpha}=\frac{1}{(\gamma-1)} V \frac{d P}{d \alpha}+\frac{\gamma}{\gamma-1} P \frac{d v}{d \alpha}
$$

Figures 22-23 show the influence of diesel and biodiesel on the maximum cylinder pressure for 1 and 3 bars imep and $800 \mathrm{rpm}$. There is no significant difference in the maximum pressure between the fuels although the peak for FAME is earlier in the power stroke by 0.5 CAD for 1 IMEP up to 2 CAD for 3 IMEP because of shorter ignition delay.

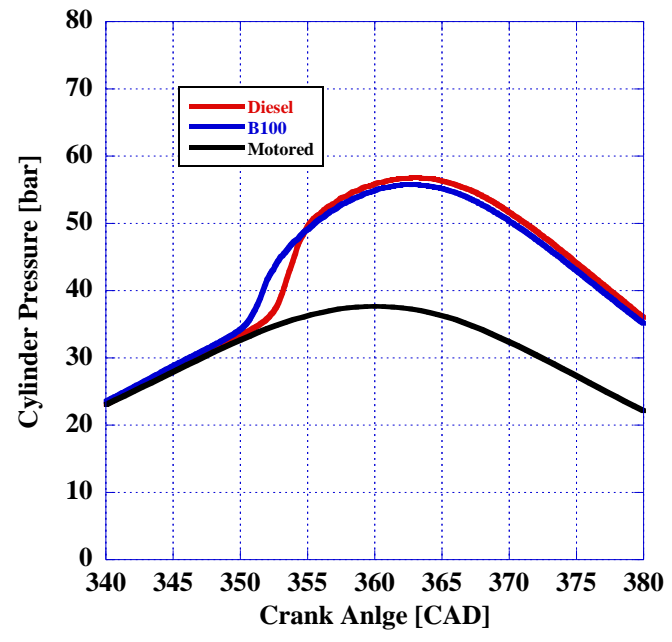

Figure 22 Cylinder pressure for Peanuts FAME vs ULSD\#2 at 1 bar imep and $800 \mathrm{rpm}$

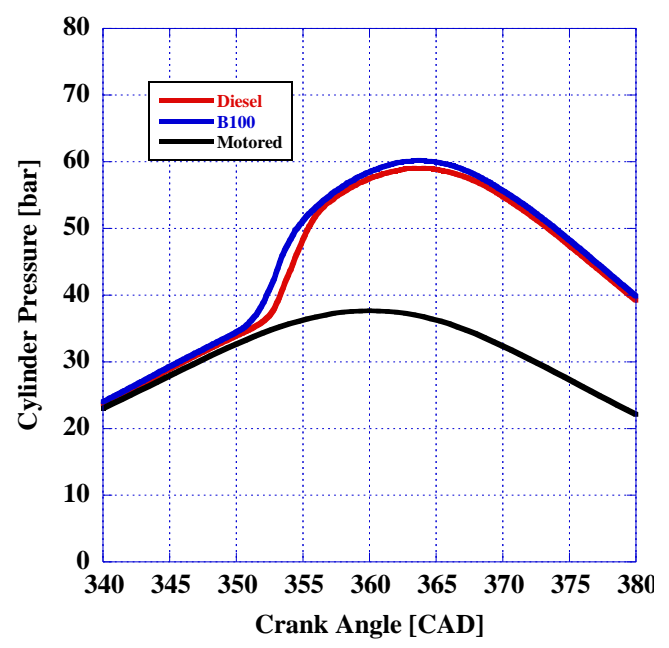

Figure 23 Cylinder pressure for Peanuts FAME vs ULSD\#2 at 3 bar imep and 800 rpm 
The net heat-release profiles in diesel and B100 fueling modes profiles are presented in Figures 24-25 and show the classical diesel combustion consisting of a premixed combustion phase followed by a diffusion controlled phase. The ignition delay for $800 \mathrm{rpm}$ and 3 IMEP was 9 CAD for USLD\#2 and 7 CAD for B100. The premixed phase for ULSD\#2 has higher values for 1 bar imep because the increased ignition delay and fuel accumulation and at 3 bars imep when the difference in ignition delay has been reduced the maximum values of AHRR are similar. The premixed burning phase is determined by the ignition delay and vaporization rate of the fuels while the diffusion combustion phase is determined by the rate of air/fuel mixing. In the high temperature combustion mode, the flames tend to initialize and propagate to regions with air/fuel ratios that are close to stoichiometric, resulting in the classical sootNOx trade-off.

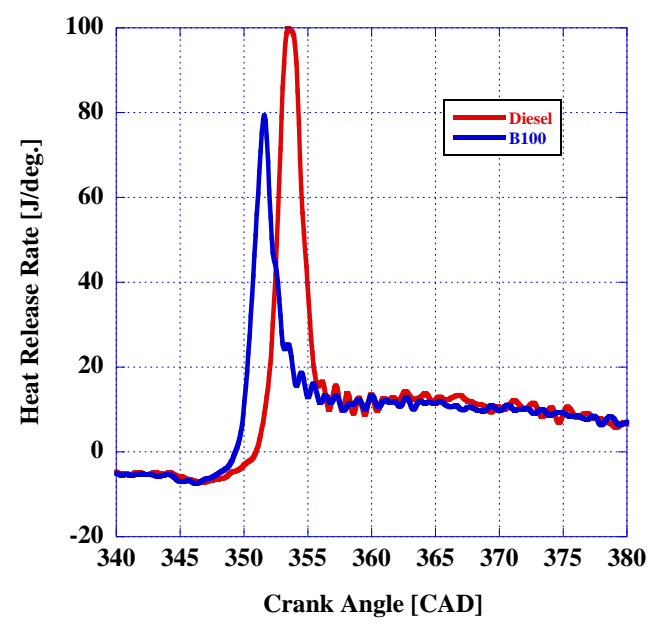

Figure 24 Apparent (net) heat release for FAME vs ULSD\#2, 1 bar imep, 800 rpm

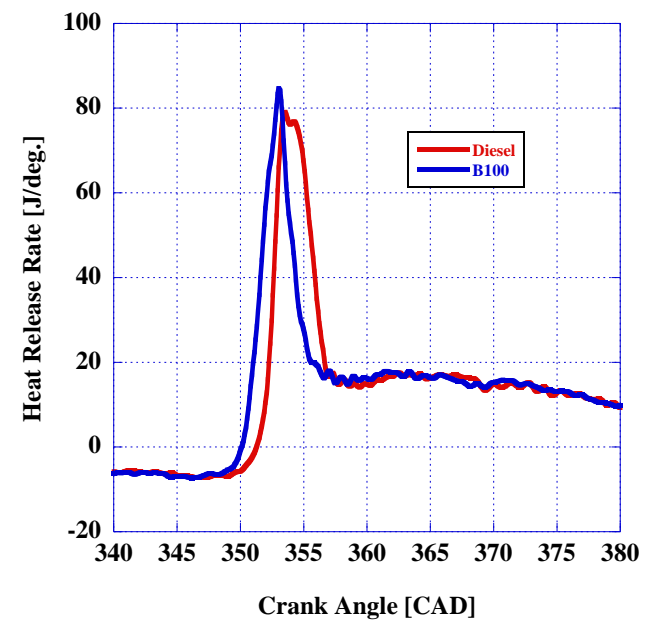

Figure 25 Apparent (net) heat release for FAME vs ULSD\#2, 3 bars imep, 800 rpm

\section{IDI Engine}

The resulting apparent heat release rates are shown in Figures 26 and 27 for the two new fuels. A characteristic negative heat release is observed from 330 to $355 \mathrm{CAD}$, the result of heat absorption and vaporization subsequent to fuel injection. Ignition occurs at the end of the ignition delay period, and the AHRR sharply rises, from the combined premixed and diffusion phases of combustion.

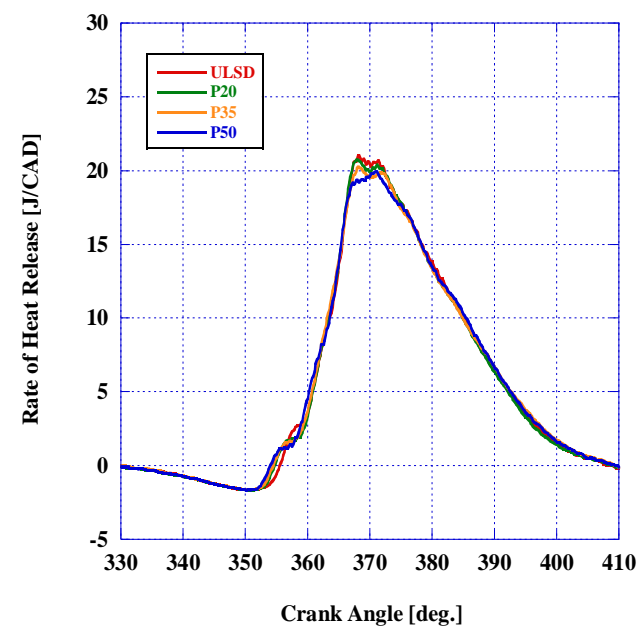

Figure 26 AHRR for Peanuts FAME vs ULSD\#2, 6.2 bars imep and $2200 \mathrm{rpm}$

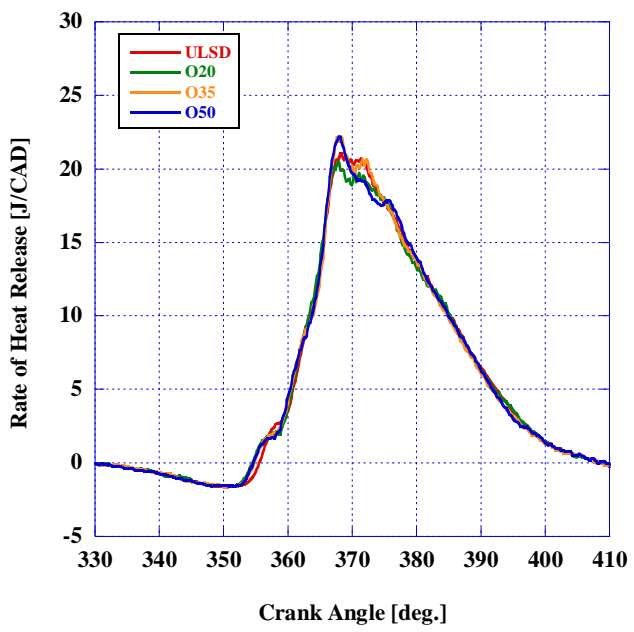

Figure 27 AHRR for Methyl Oleate vs ULSD\#2, 6.2 bars imep and $2200 \mathrm{rpm}$ 


\section{In Cylinder Mass Burnt}

\section{IDI Engine}

The ignition delay for the IDI engine was defined as the crank angle interval from the start of injection (defined as the moment the fuel line reached 147 bars, at which fuel is injected in the IDI engine or 20 BTDC for the DI engine when the injector's needle starts to raise)) to the point where $10 \%$ of the total mass was burnt (CA10). The higher viscosity of the peanut FAME leads to inferior atomization relative to petroleum diesel. The larger droplets created are expected to increase ignition delay in part due to the greater Sauter Mean Diameter (SMD) of methyl ester biodiesel, which is from $5-40 \%$ higher than for petroleum diesel fuel. Another contributing factor to the ignition delays (and opposite to the first one) is the chemical effect, where higher cetane numbers produce shorter ignition delays for FAMEs.

At the conditions tested in this study, IDI engine exhibited an almost constant ignition delay for both the peanut FAME and methyl oleate blends of approximately $1.06 \mathrm{~ms}$. Table 6 displays the $100 \%$ combustion duration in crank angle degrees for ULSD compared with peanut FAME and methyl oleate. The results show a slight increase in combustion duration with the peanut FAME blends compared with the methyl oleate blends, and an increase in both in comparison to USLD. This may suggest that the combustion propagation speed decreases with increasing FAME and methyl oleate content, as shown in Figures 28 and 29.

Table 6 Combustion Duration 0-100\% - IDI engine

\begin{tabular}{|c|c|c|c|}
\hline Fuel & $\begin{array}{c}\text { Crank Angle } \\
\text { Duration } \\
\text { [deg.] }\end{array}$ & Fuel & $\begin{array}{c}\text { Crank Angle } \\
\text { Duration } \\
\text { [deg.] }\end{array}$ \\
\hline ULSD & 58.1 & USLD & 58.1 \\
\hline P20 & 59.0 & O20 & 57.7 \\
\hline P35 & 59.1 & O35 & 57.2 \\
\hline P50 & 57.9 & O50 & 56.8 \\
\hline
\end{tabular}

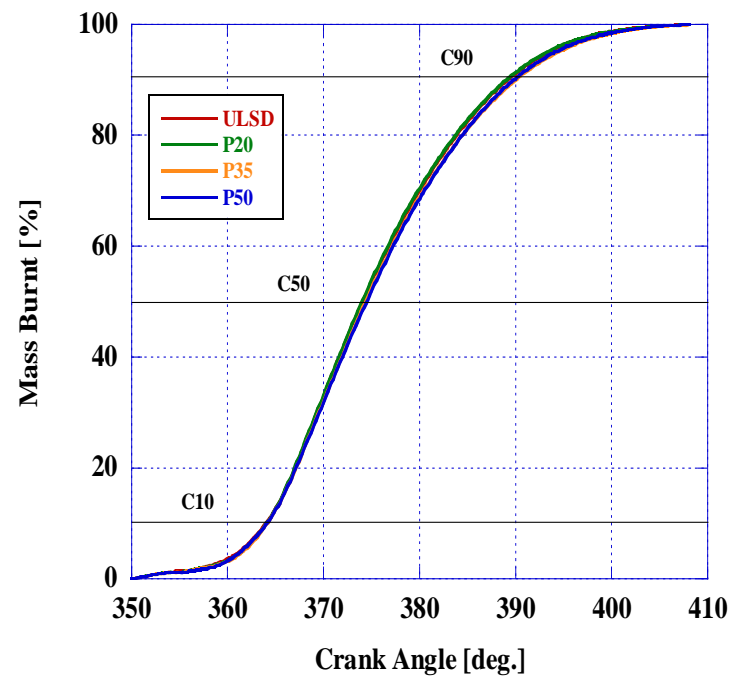

Figure 28 Mass burnt Peanuts FAME blends vs ULSD\#2. 6.2 imen. $2200 \mathrm{rbm}$

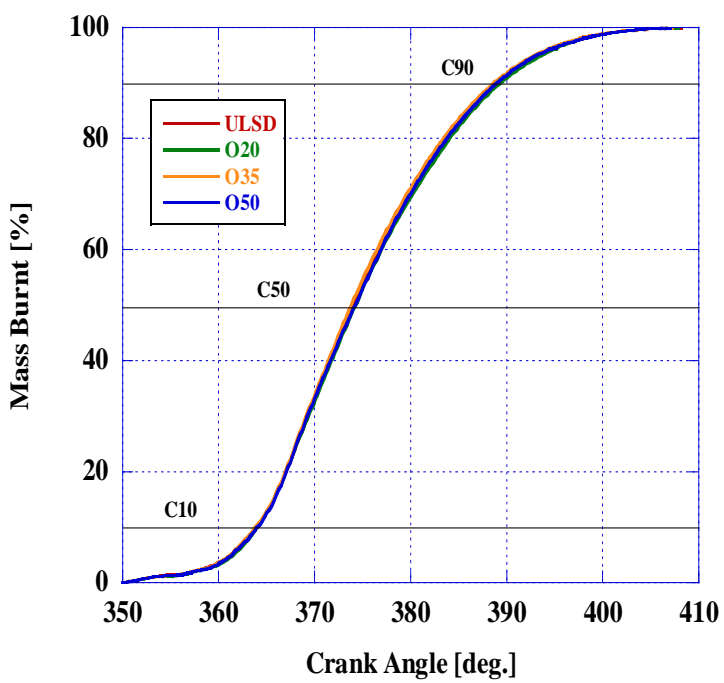

Figure 29 Mass burnt Methyl Oleate blends vs ULSD\#2 6.2 imep, $2200 \mathrm{rpm}$ 


\section{Direct Injection Engine}

The mass burnt of the USLD\#2, and B100, are shown in figures 30-31. The diesel and B100 graphs show that mass of fuel burnt increases quickly after $15^{\circ}$ BTDC in the compression stroke. ATDC, during the diffusion flame phase the rate of mass percent burnt increases slower until this phase is over. The ignition delay for the ULSD\#2 was $2 \mathrm{~ms}$ from the start of injection while the for B100 only $1.5 \mathrm{~ms}$ for 1 bar imep and the difference has been reduced by increasing load to only $0.2 \mathrm{~ms}$.

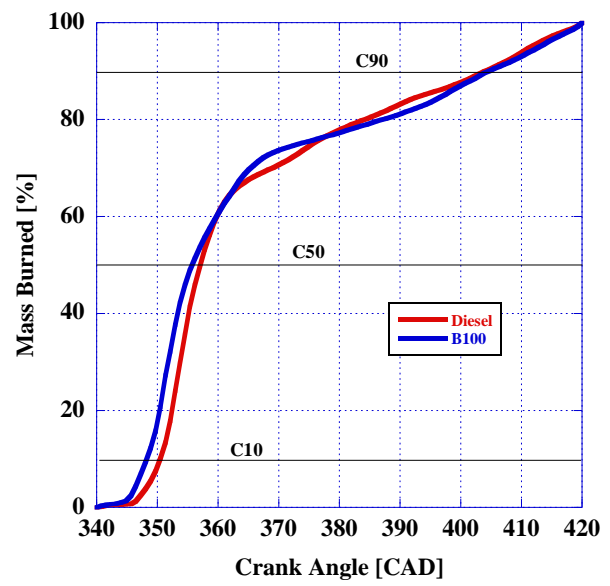

Figure 30 Mass burnt Peanuts FAME vs ULSD\#2, 1 bar imep, 800 rpm

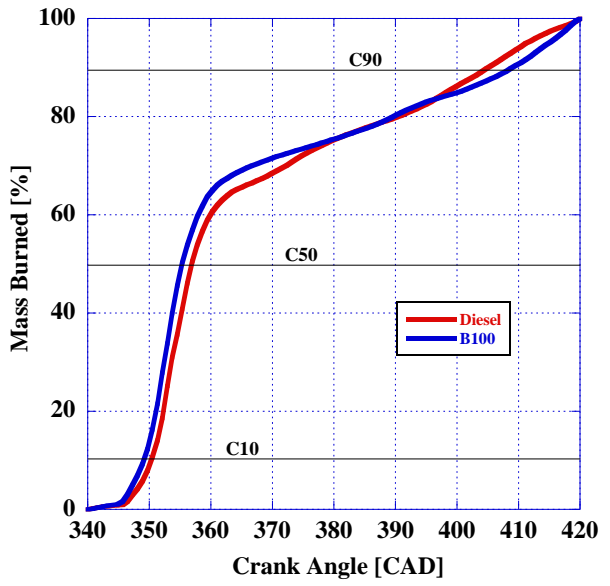

Figure 31 Mass burnt Peanuts FAME vs ULSD\#2, 3 bar imep, 800 rpm

\section{Computation of in-Cylinder Bulk Gas Temperature DI engine}

Because of temperature differences between bulk gas and the cylinder wall along with the turbulent flow within the combustion chamber, the heat transfer during combustion is quite complex [9]. The instantaneous volume-averaged gas combustion temperatures for the tested fuels throughout the cycle (calculated from the experimental pressure records) are presented in Figures 32 and 33. At low loads and idling speed the temperatures enter in a LTC regime that suggest if this temperature could be maintained emissions gains could be obtained without exhaust cleaning devices.

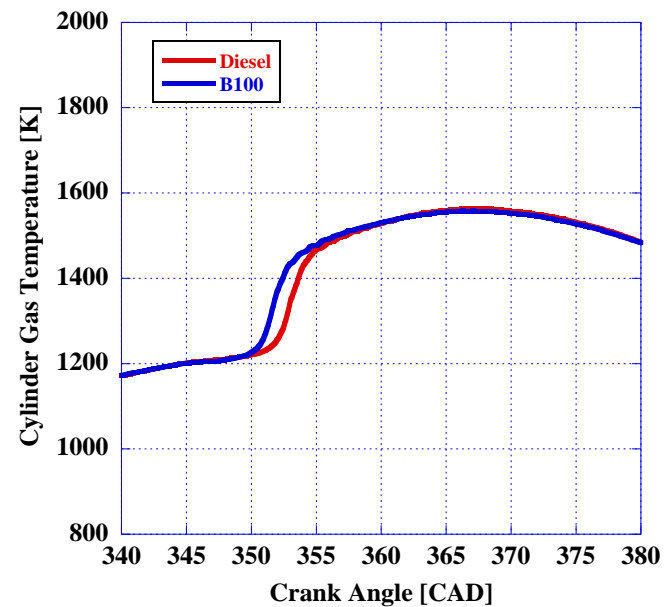

Figure 32 In cylinder temperature for Peanuts FAME vs ULSD\#2. 1 bar imen. $800 \mathrm{rbm}$

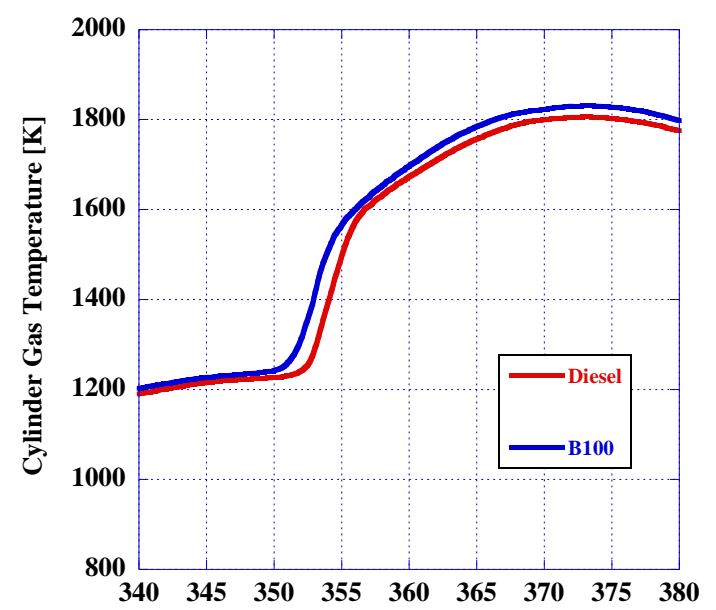

Figure 33 In cylinder temperature for Peanuts FAME vs ULSD\#2. 3 bars imen. 800 rom 


\section{IDI engine}

The maximum temperatures are almost constant for Peanuts FAME blends at $2240^{\circ} \mathrm{C}$ and show a slight increase for methyl oleate at $2250^{\circ} \mathrm{C}$, as seen in Figures 34-35.The exhaust temperature was confirmed by direct measurement in the exhaust valve port and used for the theoretical model calibration. The results showed an average exhaust gas temperature of about $375^{\circ} \mathrm{C}$ for diesel, $371^{\circ} \mathrm{C}$ for P20-P50, and $370^{\circ} \mathrm{C}$ for methyl oleate.

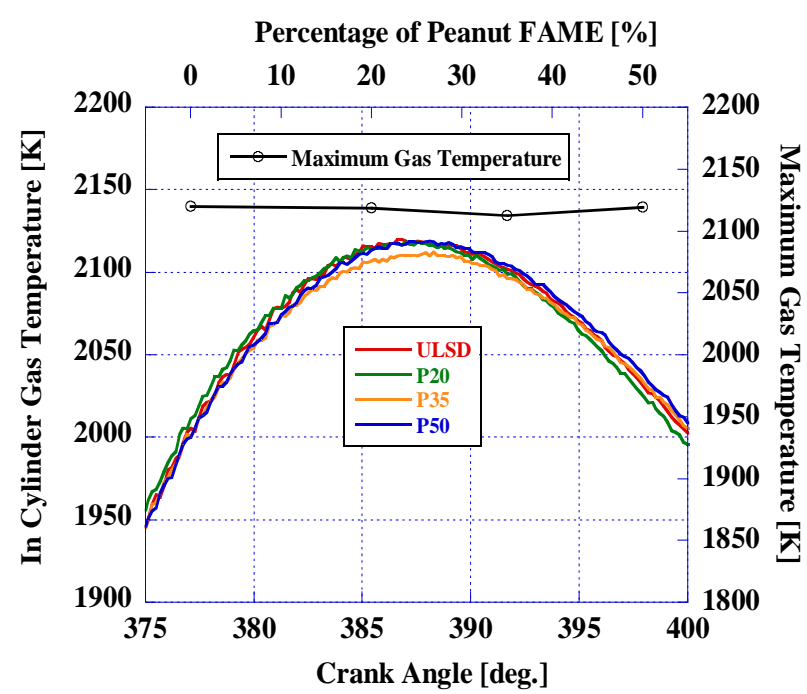

Figure 34 Maximum cycle temperature for Peanuts FAME vs ULSD\#2 at 6.2 bars imep and $2200 \mathrm{rpm}$

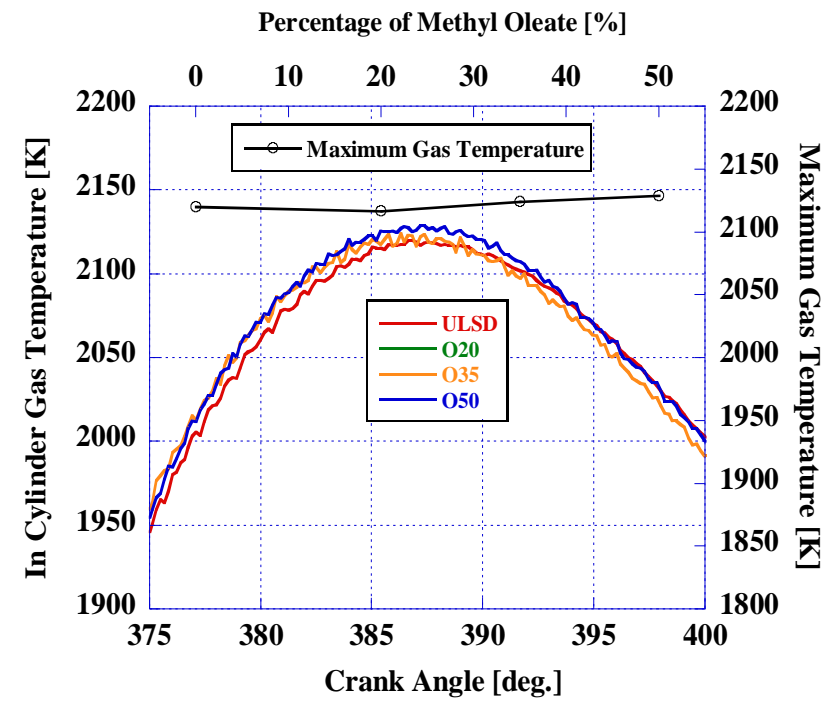

Figure 35 Maximum cycle temperature for Methyl Oleate vs ULSD\#2 at 6.2 bars imep and $2200 \mathrm{rpm}$

\section{Heat Fluxes}

In order to evaluate cylinder heat transfer, the heat fluxes are required, and for that, several parameters, such as: the instantaneous volume-averaged in-cylinder Reynolds $(\mathrm{Re})$ number that were calculated as presented in equation 5 (see explanation of terms in the Abbreviations section), the gas viscosity (equation 6), gas density and convection heat transfer coefficient (equation 8). The model for obtaining the Re number can give accurate results and shows a very sharp difference between Re number at TDC in expansion/intake stroke of about 10,000 versus 100,000 at TDC in combustion. On the other hand, the calculated Re number shown at a particular crank angle, was practically the same values for all fuels.

$$
\operatorname{Re}(\alpha)=\rho(\alpha) \frac{S \cdot N \cdot D}{30 \cdot \mu(\alpha)}
$$

Where the air viscosity is calculated with the following formula:

$$
\mu(\alpha)=4.94 \cdot \frac{1273.15+110.4}{T_{A}(\alpha)+110.4} \cdot\left(\frac{T_{A}(\alpha)}{1273.5}\right)^{1.5}-10^{-5}
$$

fluxes for all fuels were obtained by Annand model [8] further developed by Soloiu [5] and were calculated with the instantaneous volume averaged gas properties at every time step of $0.01 \mathrm{~ms}$ throughout the cycle, as presented in equation 7, where the first term represents the convection and the second term the radiation heat flux in the combustion process. It was found in [4] that the optimum results are obtained with an average piston speed compared with instantaneous piston speed.

$$
\dot{q}(\alpha)=A \frac{\lambda_{A}(\alpha)}{D} \operatorname{Re}(\alpha)^{0.7}\left(T_{A}(\alpha)-T_{w}\right)+\sigma \cdot \varepsilon\left(T_{A}{ }^{4}(\alpha)-T_{w}{ }^{4}\right)
$$




\section{DE-EE0003667 - Final Technical Report}

The convection heat transfer coefficient is displayed in the following formula:

$$
\lambda_{A}(\alpha)=-1.2775 \cdot 10^{-8} \cdot T_{A}(\alpha)+7.66696 \cdot 10^{-5} \cdot T_{A}(\alpha)+0.0044488
$$

\section{DI and IDI Engine}

The maximum convection and radiation fluxes for diesel and peanut FAME are practically the same for low load and they start to show differences as loads increase Figures 36-37. The convection flux has a maximum value earlier in the cycle compared to the radiation flux and following the zone of maximum turbulence location, while the crank angle to which the maximum radiation flux was obtained is maximally temperature dependent. For the IDI engine the values are practically identical and proving again the high tolerance to various fuels of the IDI engine.

These results fit well with the studies of Soloiu [3] and Borman and Nishiwaki [11].

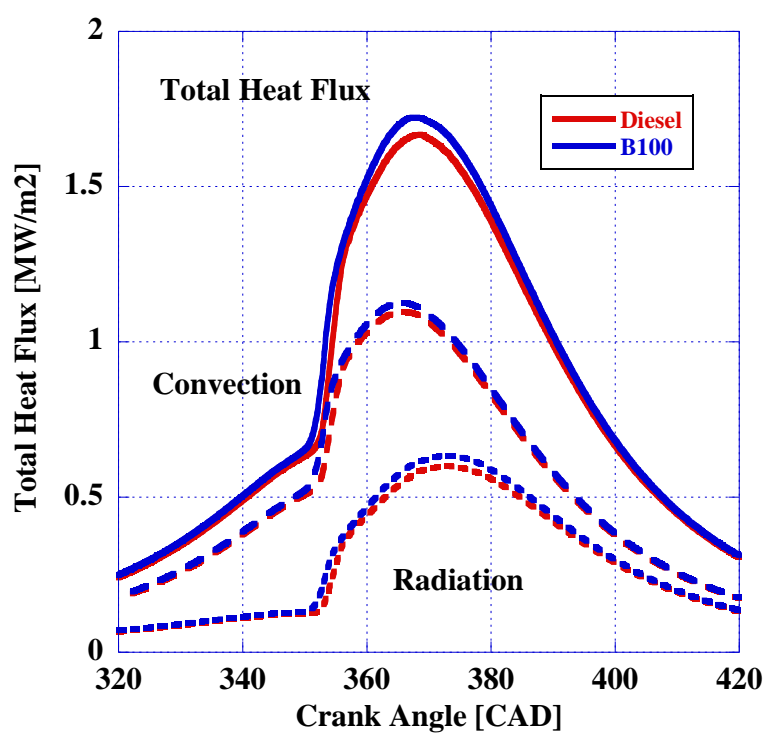

Figure 36 Heat fluxes 1 bar imep Peanuts FAME vs ULSD\#2, DI engine

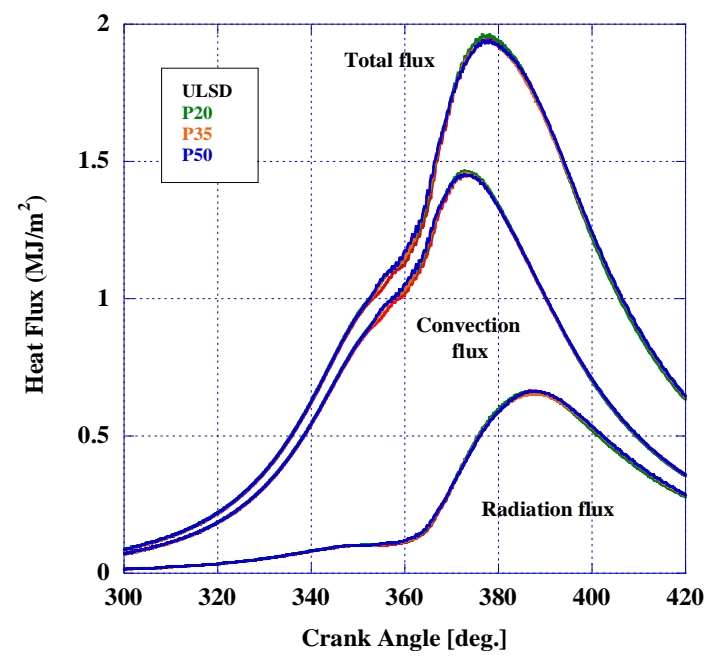

Figure 38 Heat fluxes Peanuts FAME vs ULSD\#2, IDI engine, 6.2 bars iemp, $2200 \mathrm{rpm}$

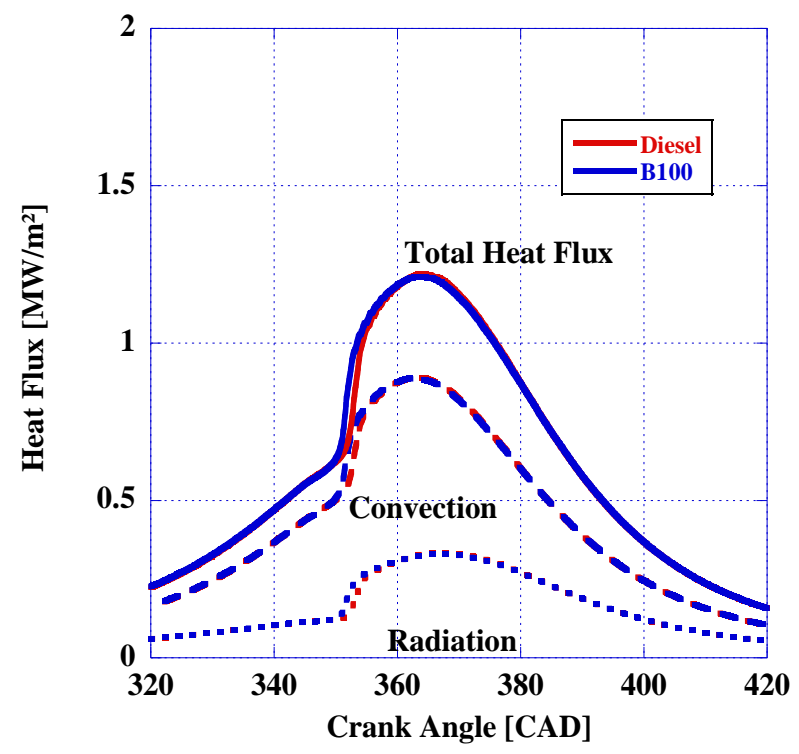

Figure 37 Heat fluxes 3 bars imep Peanuts FAME vs ULSD\#2, DI engine

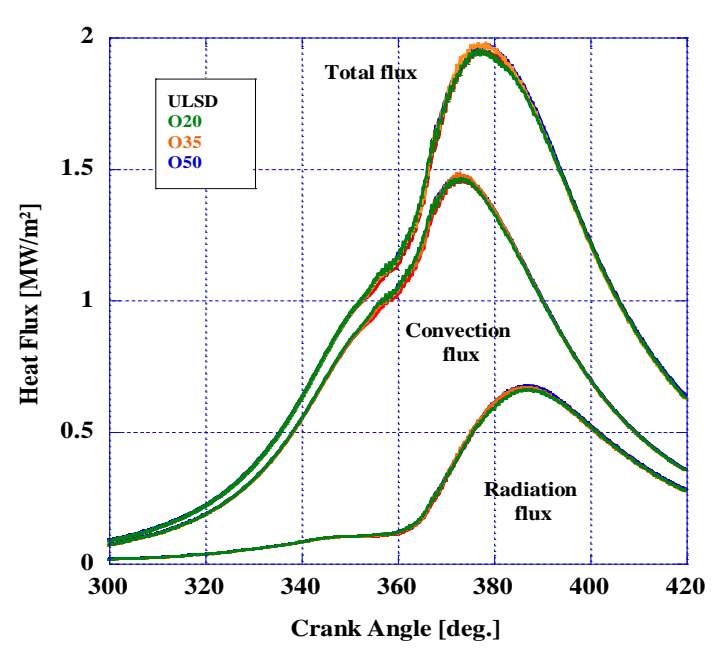

Figure 29 Heat fluxes Peanuts FAME vs ULSD\#2, IDI engine, 6.2 bars iemp, 2200rpm 


\section{The Heat Transfer}

Based on the heat fluxes, the heat transfer throughout the cycle was calculated taking into account the area of the combustion chamber exposed to the gases (the variable area of the liner + piston crown + cylinder head + piston combustion chamber) and the results are presented in Figure 40 for the DI engine with Peanuts FAME at 3 IMEP and Figures 41-42 for the IDI engine. The inner curve for each fuel, represent the apparent (net) heat release rate (AHRR). The area between the middle curve and the inner curve (red area for DI and blue for IDI) represents the energy loss from the convective heat transfer and displayed at every CAD. The area between the outer curve and the middle (blue area for DI and read area for IDI) represents the radiated heat transfer while the outer curve represents the gross heat released by combustion of fuel. While the biodiesel (B100) showed almost no heat losses for the fast heat release in the premixed charge combustion phase between 350-355 CAD, the heat losses in convection (given by middle-line) and radiation (outer line) are very visible in the power stroke Figure 40.

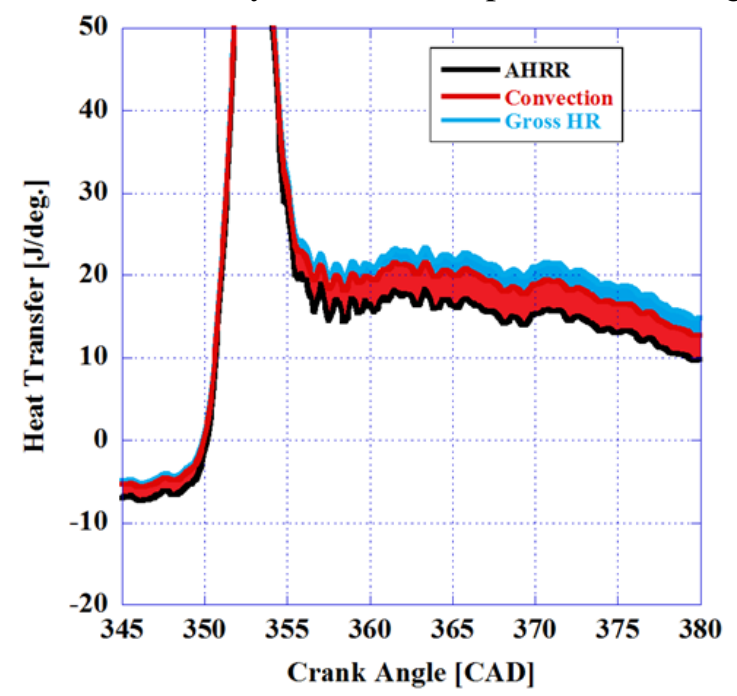

Figure 30 DI engine heat losses, Peanuts FAME, 3 bars imep, 800 rpm

For the IDI engine is very visible the heat loss from gases forced convection (blue area) in the separate combustion BTDC and immediately after TDC while radiation from soot is visible after the combustion peaked in power stroke (red area), Figures 41-42.

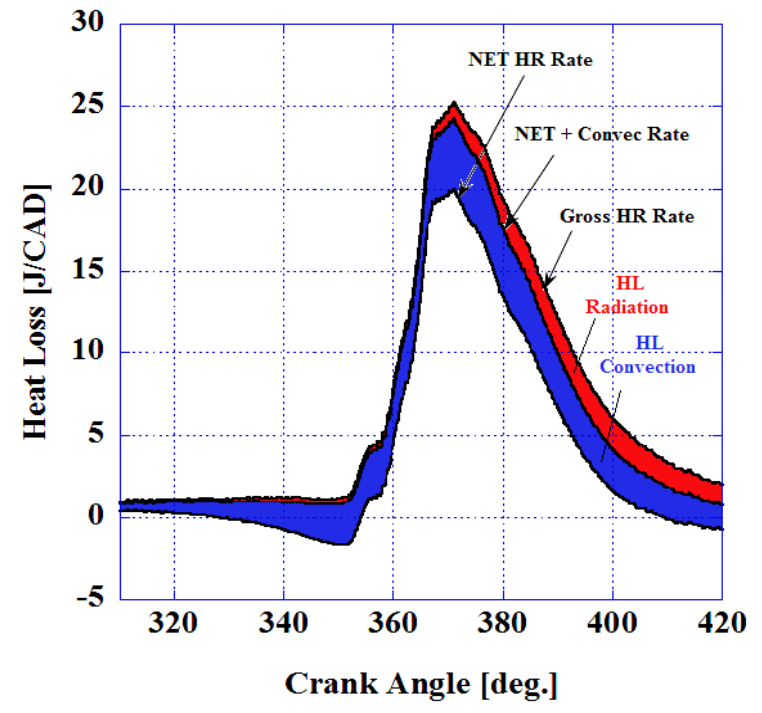

Figure 41 IDI engine heat losses, Peanuts FAME, 6.2 imep, $2200 \mathrm{rpm}$

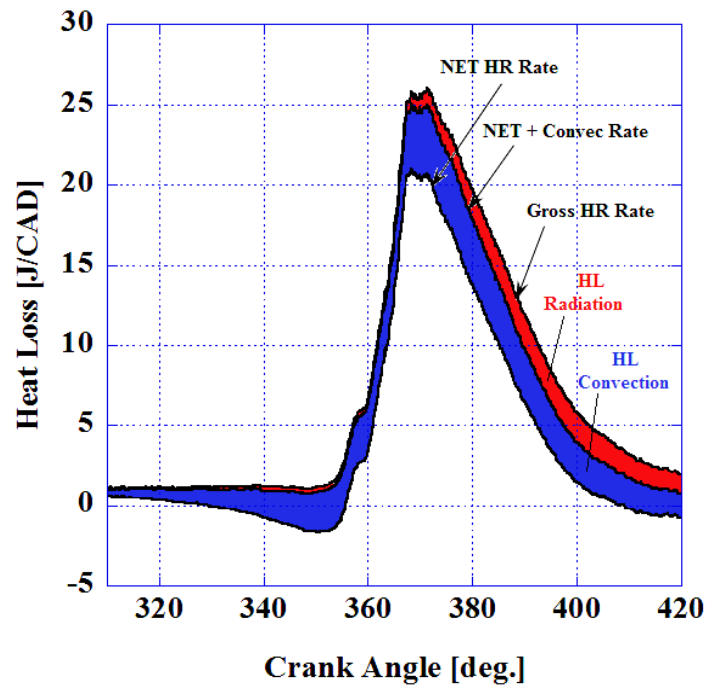

Figure 42 IDI engine heat losses, Methyl Oleate 6.2 imep, $2200 \mathrm{rpm}$ 


\section{Efficiencies}

\section{Engine}

In the DI study, the BSFC was represented by the Specific Energy Consumption per kW and hour. From Figure 43 it seems that they converge at higher loads towards the ULSD\#2 values. The overall efficiency was lower for B100 especially at low loads and at 2.5 bars imep matched and surpassed the diesel. The research could not proceed further towards higher imep due to cycle irregularities at higher loads. The engine is designed for $800 \mathrm{rpm}$ idling and a limited load range available. It was found that 3 bars imep is the limit for a stable operation at idling.

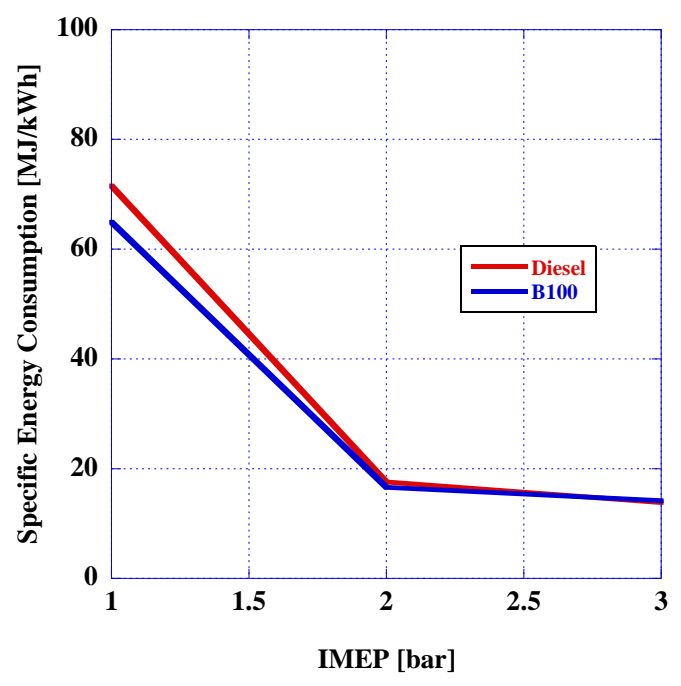

Figure 43 BSFC for DI engine for various loads at 800 rpm

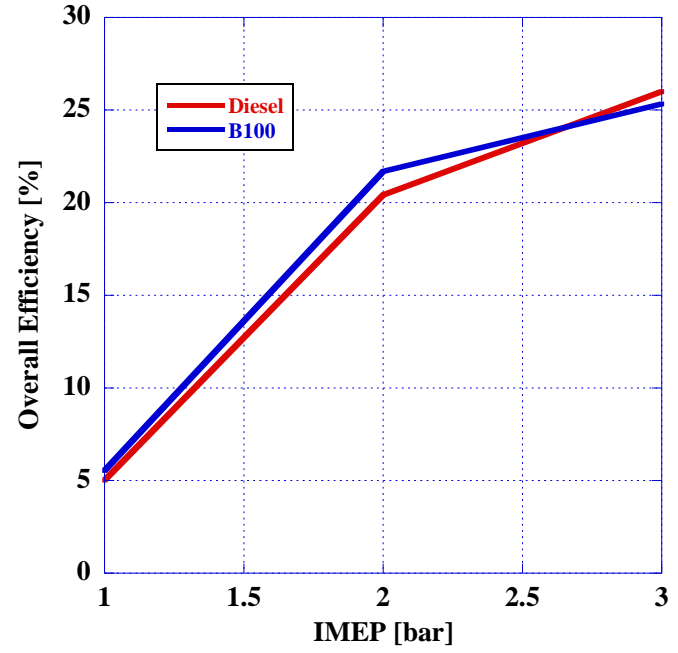

Figure 44 Overall efficiency DI engine for various loads at $800 \mathrm{rpm}$

\section{IDI Engine}

In the case of the IDI engine the mechanical efficiency for various blends looks to be constant but the bsfc $(\mathrm{g} / \mathrm{kWh})$ increases continuously while the overall efficacy is maintained constant at $30 \%$ after reaching $20 \%$ FAME content. There are no major differences between Peanuts FAME and Methyl Oleate in terms of efficiencies.

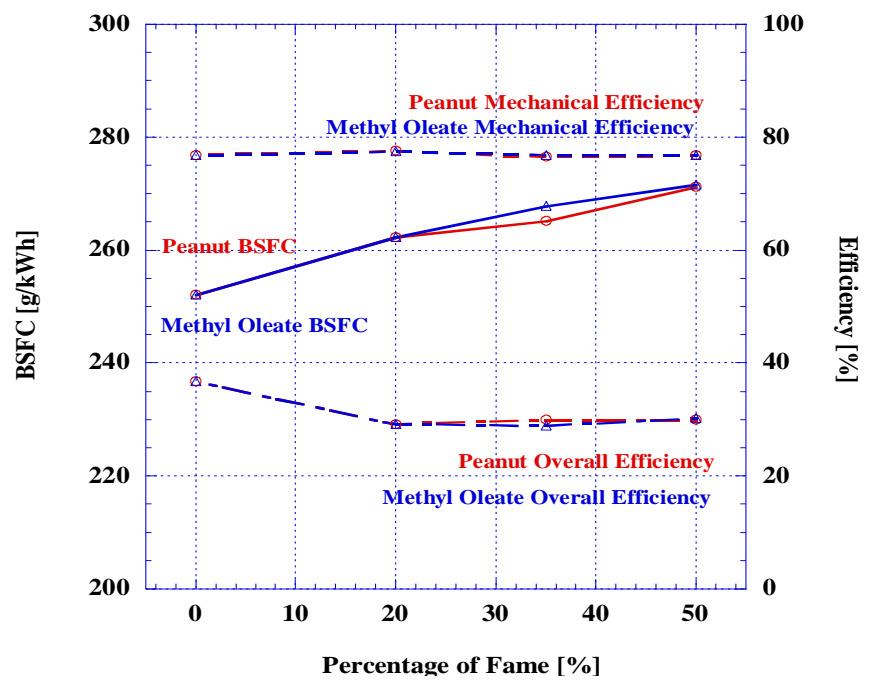

Figure 45 Overall efficiency and bsfc for IDI engine fuels with Peanuts FAME and Methyl Oleate blends, 6.2bars imep, $2200 \mathrm{rpm}$ 


\section{Task A3.0 Emissions analysis of biofuels and their neat fatty acid methyl esters}

\section{Engine}

The soot emissions show a very interesting trend, having better values for Peanuts FAME at higher loads especially because of the molecular oxygen of about $10 \%$ in the fuel, Figure 46 . The nitrogen oxides emissions are lower for low loads for biodiesel and tend towards the same values as ULSD\#2 as the loads increases, as seen in Figure 47.

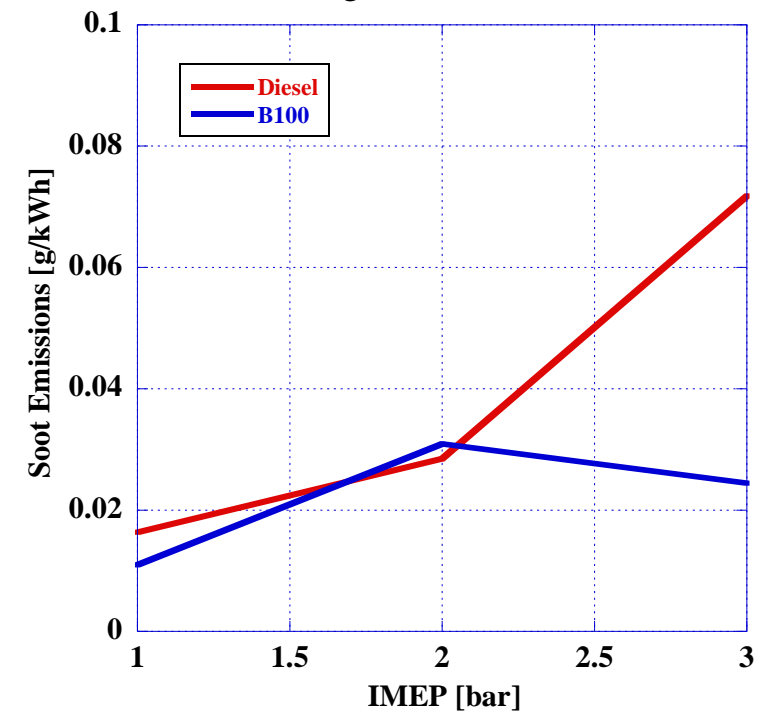

Figure 46 DI engine, Soot emissions at various loads, 800 rpm

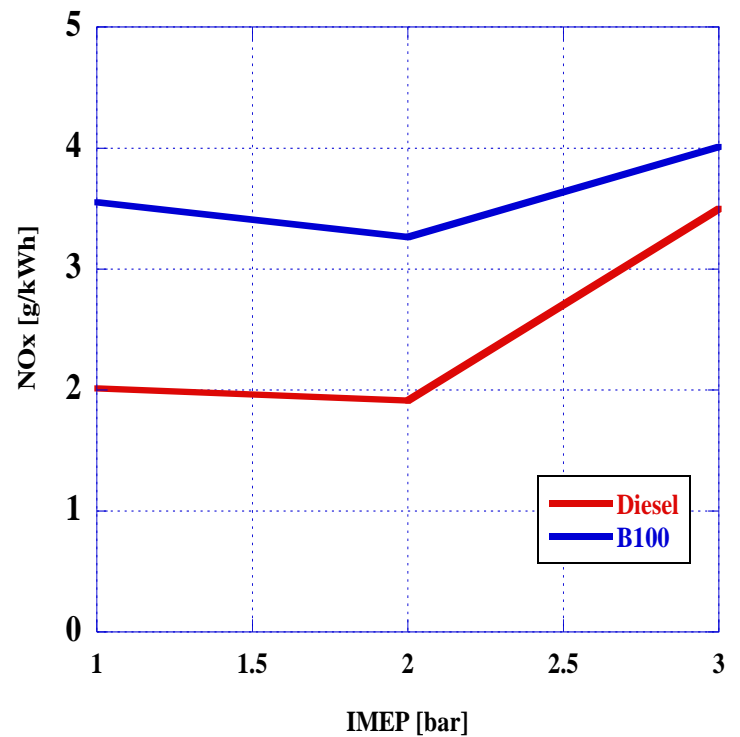

Figure 47 DI engine, NOx emissions at various loads, 800 rpm

\section{Other emissions}

In Figures 48 and 49 demonstrate the $\mathrm{CO}$ and UHC emissions and Figures 50 and 51 the formaldehyde and NMHC for the DI engine. From the results is obvious that increasing the load has a beneficial effect on the combustion efficiency. Efforts to mitigate these emissions will be undertaken in future studies.

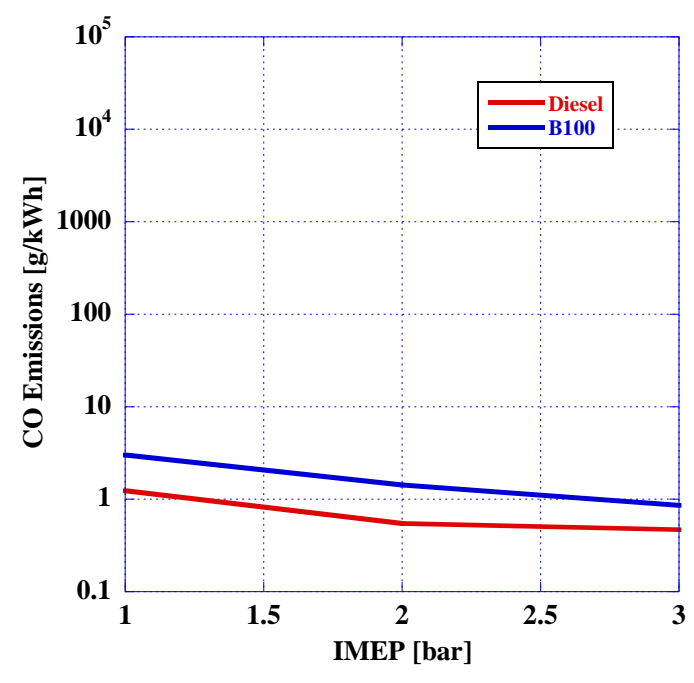

Figure 48 DI engine, $\mathrm{CO}$ emissions at various loads and 800 rpm

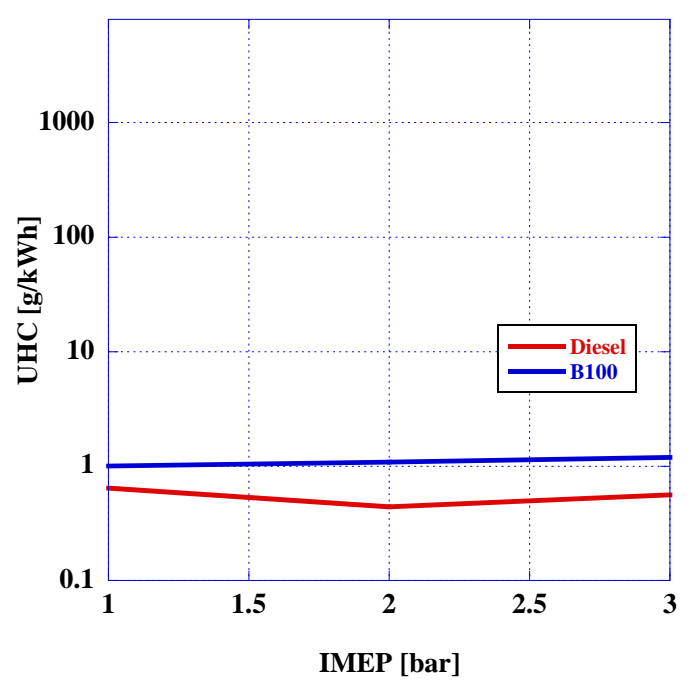

Figure 49 DI engine, UHC emissions at various loads and $800 \mathrm{rpm}$ 


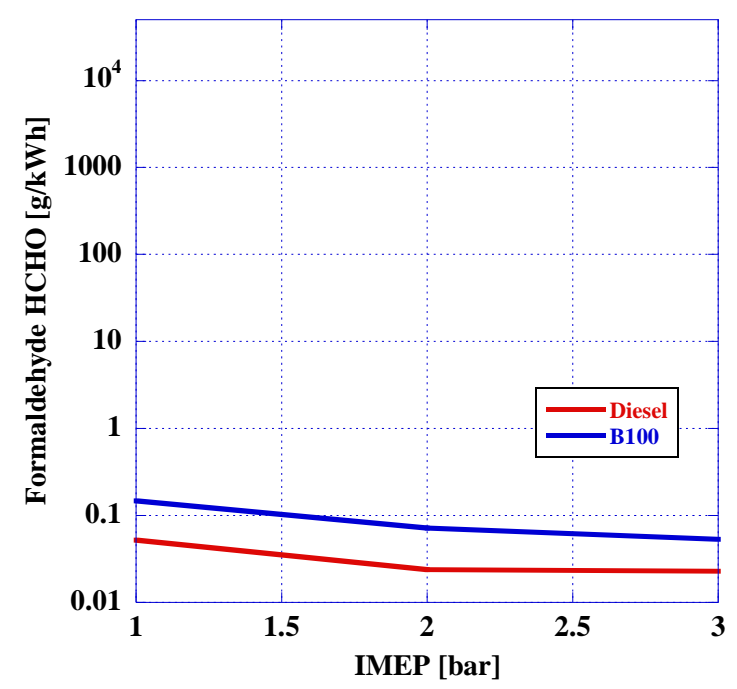

Figure 50 DI engine, formaldehyde emissions at various loads and 800 rpm

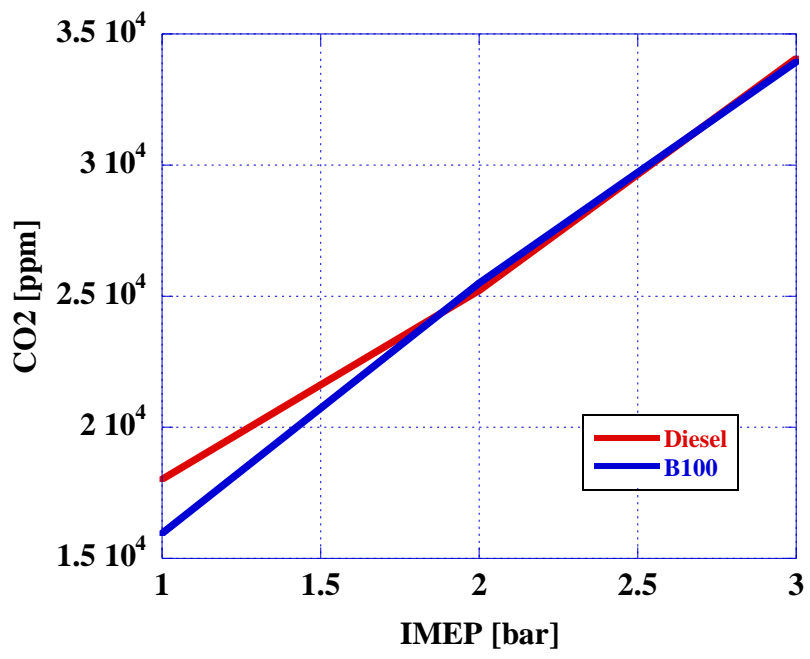

Figure 51a DI engine, $\mathrm{CO}_{2}$ emissions at various loads and 800 rpm

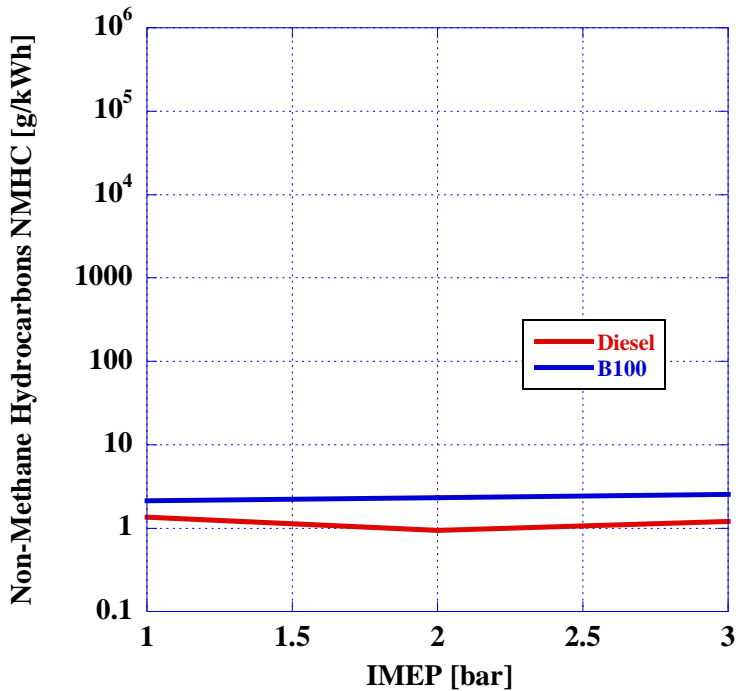

Figure 51 DI engine, NMHC emissions at various loads and 800 rpm

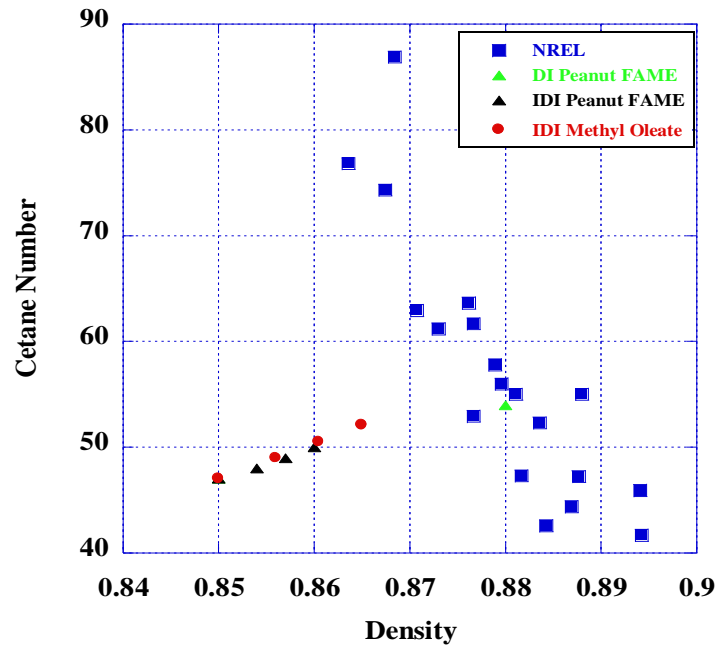

Figure $52 \mathrm{CN}$ function of fuels density

In figure 51a the $\mathrm{CO}_{2}$ emissions for the DI are presented. They follow exactly the trend of the overall efficiency and the FAME can match the ULSD\#2 performance. The values are still low because the load has been limited at 3 bars imep. The impact of molecular structure has influence of the density or cetane number. More saturated esters have higher cetane numbers and lower densities than less saturated esters. Methyl Oleate with $56 \mathrm{CN}$ and 90 Iodine number and with a density 0.88 behaves very similar with the Peanuts FAME since is its main component, Figure 52.

It seems that the lower the iodine number, the lower the NOx emission. The density of shorter chain length saturated esters is greater than longer chain saturated esters and the NOx emission is also higher. The blending effect for the NOx emissions is not straightforward and NOx emissions appear to be influenced by the blend percentage that would result in a well-defined the oxygen level. It is believed that NOx emissions are a combination of ULSD\#2 NOx and FAME NOx. The IDI engine in this study is Tier 
4 and that explains the very low NOx emissions, Fig. 53 and 54. The fuel's density can be considered as an important parameter but varying specific energy content may not be the only explanation for the NOx variation.

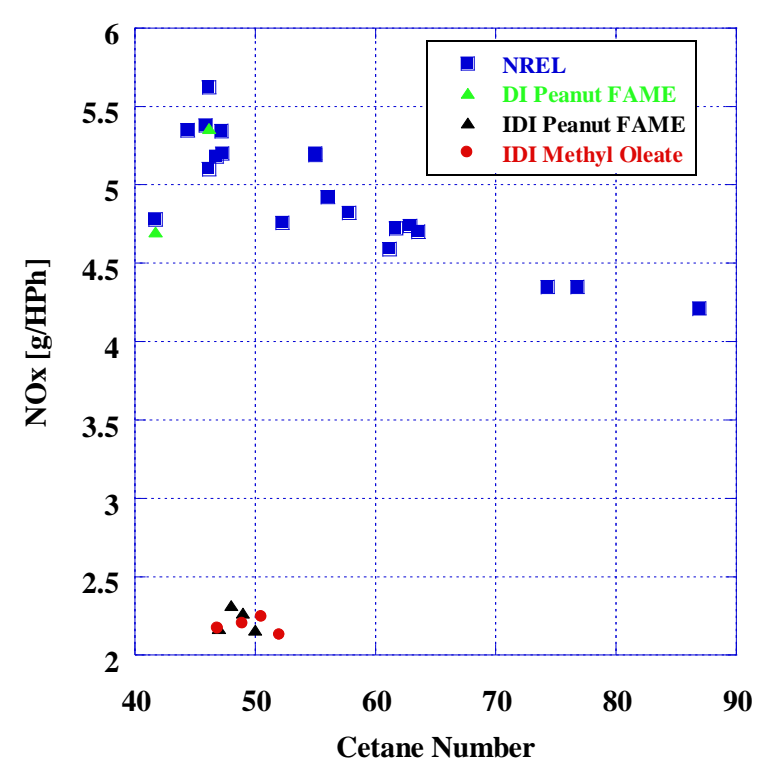

Figure 53 NOx emissions versus Cetane Number

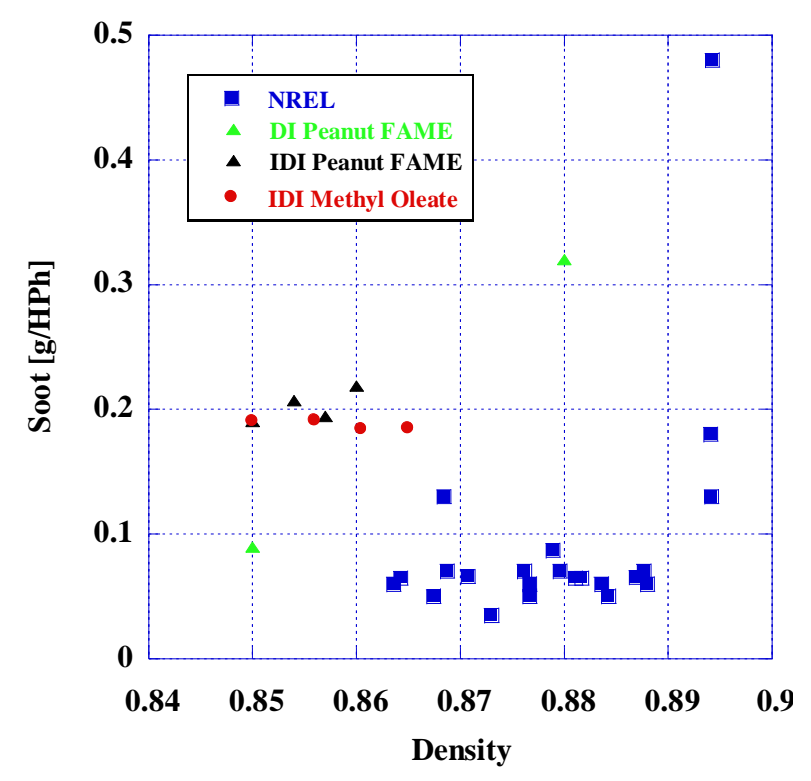

Figure 54a Soot emissions function of fuel density

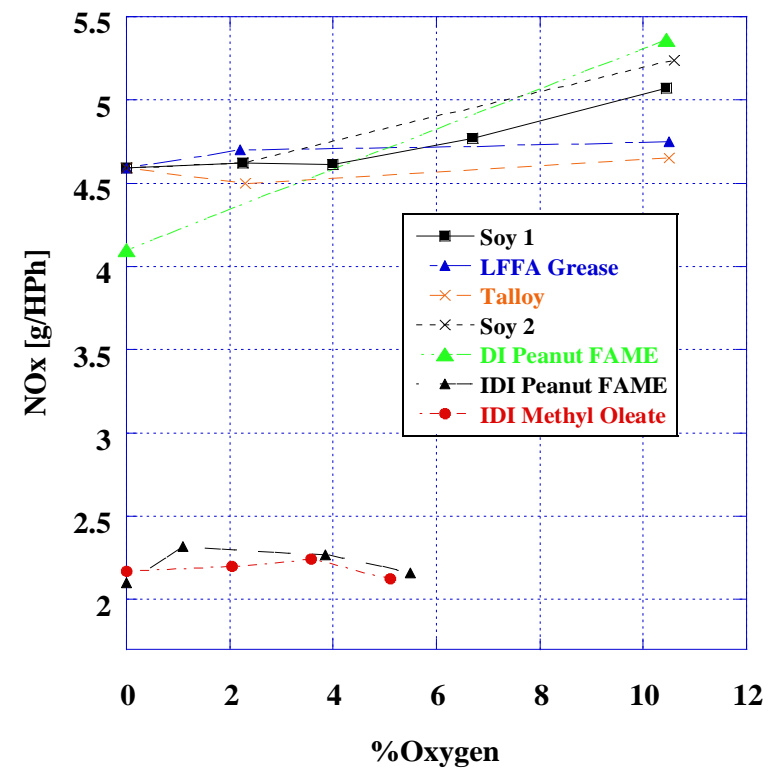

Figure 54 NOx emissions versus oxygen content

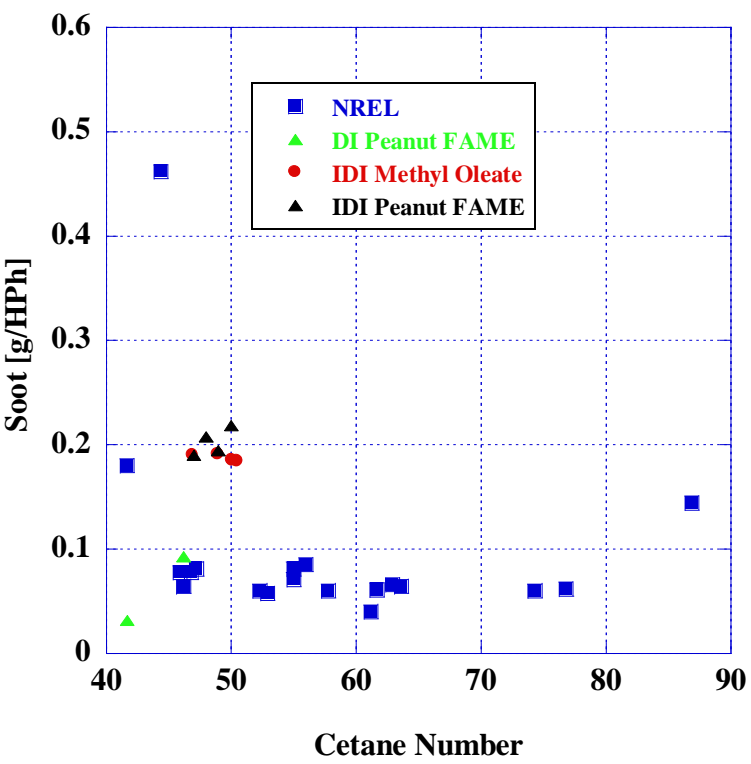

Figure 55 Soot emissions function of Cetane Number

The soot emissions show almost constant values in the case of biofuel blending: Figures 54a and 55. It seems that over density of 0.89 they increase and this may be related to higher viscosity also and low cetane number. 


\section{Task A4.0 Computer simulations of fuel injector processes}

Focusing on the complete and clean utilization of a fuel, the intent of this work was to develop a mathematical model of the spray injection and atomization of a fuel within a Diesel engine's combustion chamber and to extend it to biofuels. The development of a model for the injection process is expected to allow for a better understanding of the involved dynamics and also provide a basis for comparison between fuels for the purpose of upgrading in the future the DI engine with a system delivering higher injection pressures. In order to assess the potential of alternative fuels it is necessary to compare it to diesel fuels derived from petroleum distillates. The spray model discussed in this work was developed for ULSD and is being adapted for use with biodiesel fuels for comparison. Initial work in the comparison of spray properties for fuels with different physical properties is presented, including the effects of fuel density and kinematic viscosity on spray development: penetration, dispersion angle, etc.

\section{Fuel spray introduction}

Injection of fuel directly into the combustion chamber of a diesel engine causes atomization of the fuel and the appropriate distribution of the fuel within the air to be combusted. Injection of the fuel allows for an increase in contact surface between the air and the fuel, by hundreds of times; and the increased breakage of the fuel significantly reduces the time required for fuel and air mixing. The routing of the injected fuel also has to be taken into consideration to ensure complete utilization of the air available for combustion. Usually the injection into the cylinder starts in advance of TDC. For the studied case it was adopted at $20^{\circ} \mathrm{CA}$ before TDC because that corresponds with the setting of the DI engine in the laboratory.

The fuel atomizes through a nozzle mounted on the extremity of the injector nozzle and enters the combustion chamber. Usually the nozzle has one or more calibrated orifices with a diameter of 0.10 to 1 $\mathrm{mm}$. The fuel is delivered under pressure by the injection pump in the nozzle sac. The pressure before the atomizing orifice is named in the study injection pressure $\mathrm{p}_{\mathrm{i}}$. During the injection process, the injection pressure is variable. A fundamental parameter of the injection is $w_{0}$, the velocity of the fuel through the injection nozzle, because it marks the kinetic energy of the spray. Velocity $\mathrm{w}_{0}$ will be determined using the Bernoulli equation where $\Phi_{0}$ in the orifice flow coefficient:

$$
w_{0}=\phi_{0} \cdot \sqrt{\frac{2 \cdot \Delta \mathrm{p}}{\rho_{c}}}
$$

Fuel atomization is determined by several parameters, including:

1. Air drag at spray's penetration, which tends to break the spray and loosen into fine particles

2. Air motion within the combustion chamber, which directs the spray's motion

3. Air entrainment within the spray

4. Spray and air turbulence

Some physical properties such as surface stress and viscosity oppose atomization of the fuel.

The quality of the atomization is influenced by many factors grouped as follows:

1) Functional parameters of the injection system taken into account:

- Injection pressure $\mathrm{p}_{\mathrm{i}}$;

- Injection velocity $\mathrm{w}_{0}$;

- Rotating speed of the injection pump $\mathrm{n}_{\mathrm{p}}$;

- Stroke of the injection needle $\mathrm{h}_{\mathrm{ac}}$;

2) State of the injection medium:

- Pressure, $\mathrm{p}_{\mathrm{a}}$, of the cylinder air (counter-pressure);

- Temperature, $\mathrm{T}_{\mathrm{a}}$, of the air in the cylinder;

- Actual Density of the air in the cylinder, $\rho_{\mathrm{a}}$; 
- Air swirl number, $\omega$.

3) Physical properties of the fuel:

- Surface stress, $\sigma_{c}$;

- Dynamic viscosity, $\eta_{c}$

- Fuel density $\rho_{c}$;

- Fuel temperature, $T_{c}$.

4) Design of the injection system:

- Cam shape;

- Injection pump's type;

- Injection nozzle's type;

- Number and dimensions of the nozzle's orifices.

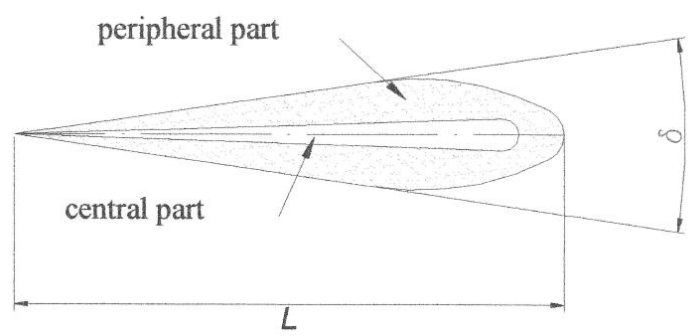

Figure 56 Schematic of the fuel spray

The fuel spray is characterized by four main characteristics: 1) fineness, diffusion and atomization 2) uniformity of atomization 3) penetration and 4) dispersion angle of the spray. The first two parameters hold an important role in the evaporation process, while the last two are important for the mixing process.

Fineness of atomization regards the degree of breakage of the fuel spray into droplets measured by the average diameter of the fuel particles. Diesel engines claim a high degree of atomization, characterized by a mean droplet diameter of 10 to $30 \mu \mathrm{m}$. For evaporation calculation of Sauter Mean Diameter is used, which represents six times the ratio between the volume of the drops and the area of the drops. Analyzing the experimental data in simple simulation conditions, in high pressure chambers [12], gave the following relationship for the Sauter Mean Diameter:

$$
d_{32}=1.445 \cdot \frac{d_{0}^{0.6607} \cdot \sigma_{c}^{0.1927} \cdot \eta_{c}^{0.1466}}{\rho_{a}^{0.266} \cdot \rho_{c}^{0.0733} \cdot w_{0}^{0.532}}
$$

Another relationship for the Sauter mean diameter developed by Tang-Wei Kuo from General Motors [13] is given as:

$$
\mathrm{SMD}=23.9 \cdot \Delta p^{-0.135} \cdot \rho_{\mathrm{a}}^{0.12} \cdot m_{\mathrm{c}}^{0.131}
$$

The role played by the diameter of the injection nozzle, $\mathrm{d}_{0}$, injection velocity, $\mathrm{w}_{0}$, and the number of orifices in the injection nozzle in atomization of Diesel fuel is described by Grunwald [12]. It can be noticed that the mean diameter of droplets in fuel spray is lower with a smaller diameter of the injection nozzle and with a larger value of the injection velocity. A larger number of orifices in the injector nozzle create a more favorable atomization. Uniformity of atomization is used to refer to the frequency of appearance of drops around a mean diameter $\mathrm{d}_{\mathrm{su}}$, where $\mathrm{d}_{\mathrm{su}}$ represents the most probable mean diameter. Spray penetration refers to the distance L (Figures 56, 57), movement of the frontal part of the spray in a given time. Penetration must be chosen such that during the injection time the spray must travel through the entire combustion chamber without impingement on the cold walls of the cylinder (case 3 from figure 


\section{DE-EE0003667 - Final Technical Report}

57). If the penetration is high, the fuel reaches the cylinder wall causing incomplete burning, soot deposits in the chamber, and smoke in the exhaust gas (case 1 from Figure 57). The cylinder also suffers in this situation from slow chemical erosion. On the other hand, if the penetration of the fuel is low, peripheral air zones remain and the fuel has an incomplete combustion even though there is excess air in the combustion chamber (case 2 from Figure 57).

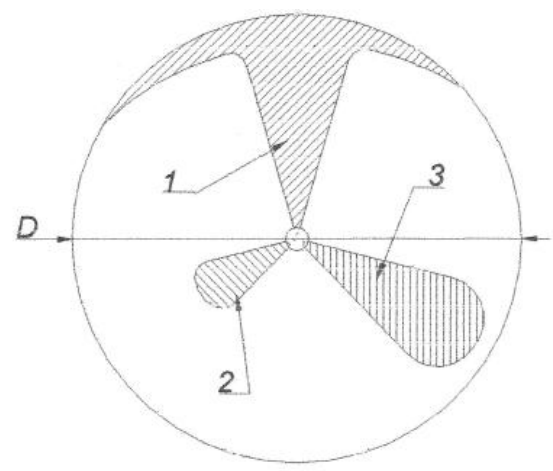

Figure 57 Wall impingement of the spray

Penetration is considered to determine the structure of the spray, which is modified over time. Two structures were highlighted in Figure 56; an initial structure of the spray comprised of a liquid core, and an envelope of droplets that is determined by a continuous diffusion process. Only the fuel cloud defines the final structure of the spray. Accordingly, the spray penetration takes place in two stages and Kamimoto [14] proposed relations for diffusion as follows where $\delta$ is the angle of dispersion of the spray:

$$
P=\sqrt{\frac{4 \cdot m_{c} \cdot t}{\pi \cdot d_{o} \cdot \sqrt{\rho_{c} \cdot \rho_{a}} \cdot \tan \left(\frac{\delta}{2}\right)}}
$$

Hiroyasu [15] described the initial and final stages of spray evolution with:

$$
\begin{aligned}
P_{i} & =\phi_{10} \cdot \sqrt{\frac{2 \cdot \Delta p}{\rho_{c}} \cdot t} \\
P_{f} & =2.95 \cdot\left(\frac{\Delta p}{\rho_{a}}\right)^{\frac{1}{4}} \cdot \sqrt{d_{0} \cdot t}
\end{aligned}
$$

Hiroyasu [15] also offers the time relationship to fuel spray disintegration:

$$
t_{d}=28.65 \cdot \frac{\rho_{c} \cdot d_{0}}{\sqrt{\rho_{a} \cdot \Delta p}}
$$

Apostolescu [5] proposes the relationship for spray diffusion as follows: 


$$
P=17.28 \cdot\left[\left(\frac{\Delta p}{\rho_{a}}\right)^{0.5} \cdot d_{0} \cdot t\right]^{0.5}
$$

Hiroyasu uses the assumption that the fuel spray is composed of many co-axial packages (L) emerging from the nozzle's orifice. Using this assumption one can define the penetration of all of the fuel packages forming the spray, not only the central packages, Figure 58. The calculation and simplified spray scheme are presented below.

$$
P_{L}=P \cdot e^{-4 \cdot 403 \cdot 10^{-3} \cdot(L-1)^{2}}
$$

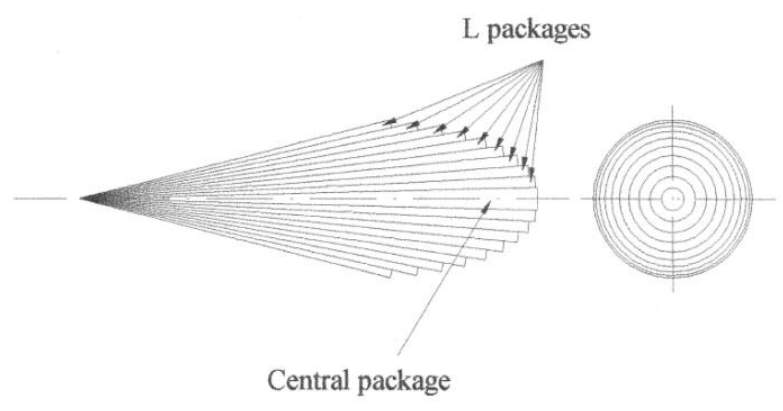

Figure 58 Scheme of fuel packages

In the case that the spray is developed in an air circular motion called swirl motion, spray penetration decreases compared with the case of spray into a stagnant atmosphere. Hiroyasu [15] defines the coefficient for the spray deviation in the swirl:

$$
C_{s}=\left(1+\frac{2 \cdot \pi \cdot r_{s} \cdot n \cdot P_{f}}{U_{i}}\right)^{-1}
$$

where:

$\mathrm{r}_{\mathrm{S}}$ represents swirl number;

$\mathrm{n}$ represents nominal rotation speed of the engine;

$\mathrm{U}_{\mathrm{i}}$ represents the initial velocity of the spray.

In this case the penetration in swirl motion is determined using the relation:

$$
P_{s}=C_{s} \cdot P_{f}
$$

Dispersion angle of the spray is the angle formed by the tangents to the spray margins emerging from the diffuser orifice. Dispersion angle $\delta$, as well as penetration P, gives an idea of the fuel distribution in the combustion chamber. In the case of the studied engine, for which the diffuser orifice is controlled by a needle, a formula for the dispersion angle is proposed by Grunwald [12] as:

$$
\delta=2 \cdot a \cdot \tan \left(\frac{0.0112 \cdot d_{0}^{0.39} \cdot w_{0}^{0.64} \cdot \rho_{a}^{0.5}}{\rho_{c}^{0.11} \cdot \eta_{c}^{0.14} \cdot \sigma_{c}^{0.25}}\right)
$$




\section{Modeling the fuel spray}

\section{Conditions and Imposed Parameters}

Initially the fuel used (injected) is a common ULSD\#2 fuel with the following physical properties:

-density: $\rho_{c}=860 \frac{\mathrm{kg}}{\mathrm{m}^{3}}$ dynamic viscosity: $\eta_{c}=0.558 \mathrm{cP}$-surface stress: $\sigma_{c}=29 \cdot 10^{-4} \frac{\mathrm{daN}}{\mathrm{m}}$

The air medium for injection has the following properties at $340^{\circ} \mathrm{CA}(20 \mathrm{CAD} \mathrm{BTDC})$ :

-air pressure (counter pressure): $P_{a}=2.361 \mathrm{MPa}$; -cylinder air temperature: $\mathrm{T}_{\mathrm{a}}=731^{\circ} \mathrm{K}$

-cylinder air density at specified CA $\rho_{a}=11.264 \frac{\mathrm{kg}}{\mathrm{m}^{3}}$

There were four injection pressures investigated all upgrade of the original $20 \mathrm{MPa}$ of the engine, and for each of them the effects on the fuel spray were calculated. The injection pressures studied were:

$$
\mathrm{P}_{\mathrm{i} 1}=110 \mathrm{MPa} ; \mathrm{P}_{\mathrm{i} 2}=82 \mathrm{MPa} ; \mathrm{P}_{\mathrm{i} 3}=50 \mathrm{MPa} ; \mathrm{P}_{\mathrm{i} 4}=30 \mathrm{MPa}
$$

For simplification is has been considered that the injection was started at a fixed time of $340^{\circ} \mathrm{CA}$; and for each injection pressure an injection time has been chosen from 20-35 CAD resulting for the injection times at the maximum speed of the engine of 2200rpm

$$
\begin{aligned}
t_{i n j} & =1.587 \mathrm{~ms} \\
t_{i n j} & =1.983 \mathrm{~ms} \\
t_{i n j} & =2.38 \mathrm{~ms} \\
t_{i n j} & =2.777 \mathrm{~ms}
\end{aligned}
$$

\section{Modeling of the Fuel Spray}

In order to calculate the diameters of the nozzle orifices it is necessary to determine the volume of the fuel injected and the injection rate, where:

$$
V_{c}=\frac{m_{c}}{\rho_{c}}(21) \text { and the initial velocity of the spray is: } w_{0_{j}}=0.75 \cdot \sqrt{\frac{2 \cdot \Delta p_{j}}{\rho_{c}}}
$$

Taking into account that the atomizer number of orifices, the orifice diameters are calculated according to the injection pressures $p_{i j}$ :

$$
d_{0 j}=\sqrt{\frac{4 \cdot a_{0 j}}{\pi \cdot z}}
$$

where the total area of the nozzle's orifices is:

$$
a_{0}=\frac{V_{c}}{w_{0} \cdot t_{i n j}}
$$

Taking into account the above, coefficient $\lambda$ (relative air-fuel ratio in the spray cloud) can be determined. The calculation relation of average $\lambda$ given by Kamimoto [14] takes into account the conical shape of the spray. The spray is defined by the dispersion angle and the spray length; so the resulting average excess air coefficient of the spray is:

$$
\lambda=\frac{1}{3} \cdot \frac{\sqrt{\frac{\tan \left(\frac{\delta}{2}\right)}{\pi} \cdot \rho_{a} \cdot\left(\frac{4}{\rho_{c} \cdot d_{0}}\right)^{\frac{3}{2}} \cdot \sqrt{m_{c} \cdot t}}}{\left(\frac{m_{a}}{m_{f}}\right)_{s t}}
$$




\section{DE-EE0003667 - Final Technical Report}

Spray penetration in stagnant atmosphere as well as in swirl motion was calculated using the relation presented in the subchapter entitled fuel spray introduction.

In the case of injection with swirl motion, the deflection radius of the spray represents the distance of the new center of spray mass from the axis of symmetry of the spray case that evolved in a stagnant atmosphere. The relationship for determining deflection was given by Tang-Wei Kuo [13]

$$
r_{\text {def }}=P \cdot \frac{m_{a}}{m_{a}+m_{c}} \cdot \frac{n \cdot r \cdot 2 \cdot \pi \cdot P}{\frac{U_{i}+U_{0}}{2}}
$$

where $\mathrm{U}_{0}$ represents the spray speed as a function of time:

$$
U_{0}=2.95 \cdot\left(\frac{\Delta p}{\rho_{a}}\right)^{\frac{1}{4}} \cdot d_{0}^{\frac{1}{2}} \cdot \frac{1}{2 \cdot \sqrt{t}}
$$

Tnag-Wei Kuo [13] defines also the mass of air that is entrained in the spray with the relation:

$$
m_{a}=m_{c} \cdot\left(U_{0} \cdot\left(\frac{d t}{d P}-1\right)\right)
$$

A theory presented by Apostolescu [16] includes the existence of a certain distribution of spray velocity into the radial sections of the spray, which he outlines in the relationship:

$$
u_{j}=u_{\max } \cdot\left[1-\left(\frac{r}{r_{j}}\right)\right]^{\frac{1}{5}}
$$

where $\mathrm{u}_{\max }$ represents the maximum speed of fuel in the spray center along the liquid core axis.

The above relation is true throughout the entire injection; however, when the spray detaches from the diffuser the theory does not hold true.

The density distribution of the fuel within the spray is defined by a relation similar to that of the velocity distribution; this similarity inspired the hypothesis that the central zone of the spray, with radius of zero, holds the maximum fuel concentration. Calculus relation for the radial distribution of density is given by Apostolescu [16] as:

$$
c_{j}=c_{\max } \cdot\left[1-\left(\frac{r}{r_{j}}\right)^{1.5}\right]
$$

where $c_{\max }$ is 1 in the center of the spray.

\section{Graphical representations of the results}

The following figures are graphical representations of the results obtained from calculation. The figures were constructed using AutoCAD software in both two and three dimensional models. 


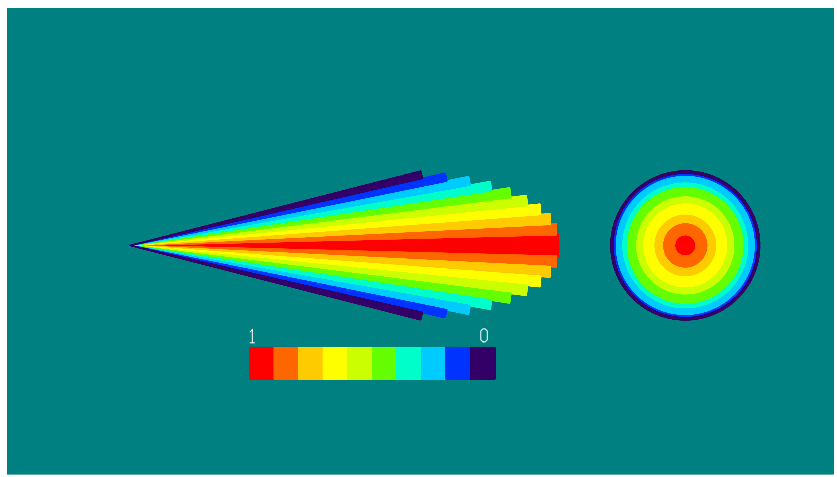

Figure 59: Radial distribution of fuel concentration
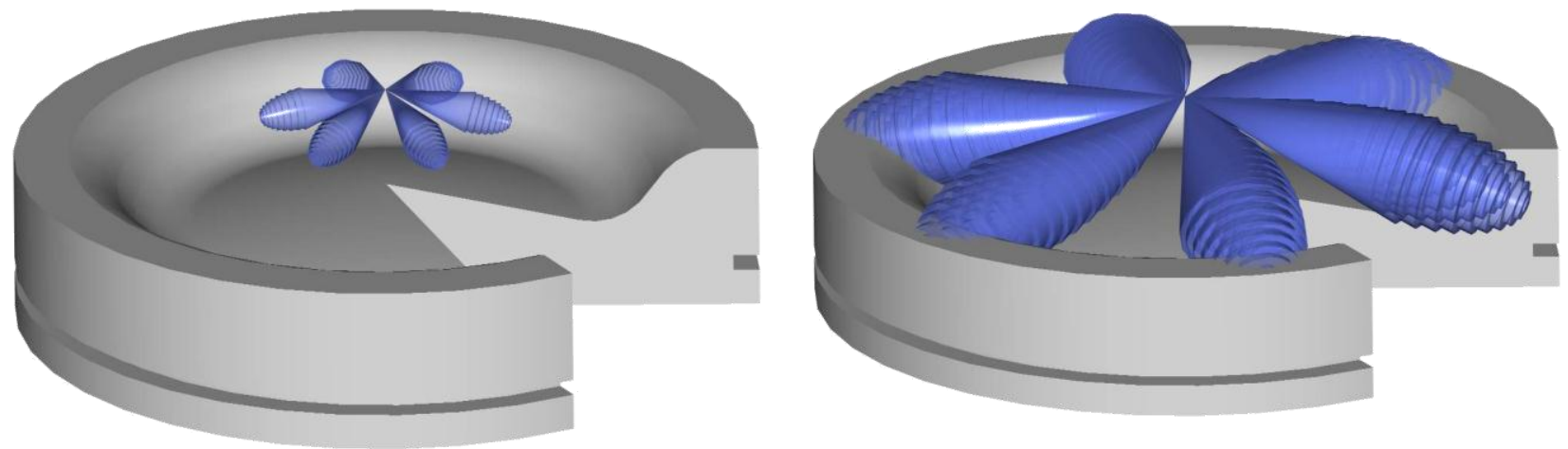

Figure 60 Evolution of the fuel spray in high swirl $(\omega=3) ; \alpha=18.75^{\circ} \mathrm{CAD}$ BTDC; $P_{i n j}=110 \mathrm{MPa} ; t=0.1 \mathrm{~ms}$ at left and $t=0.7 \mathrm{~ms}$ at right; Side view
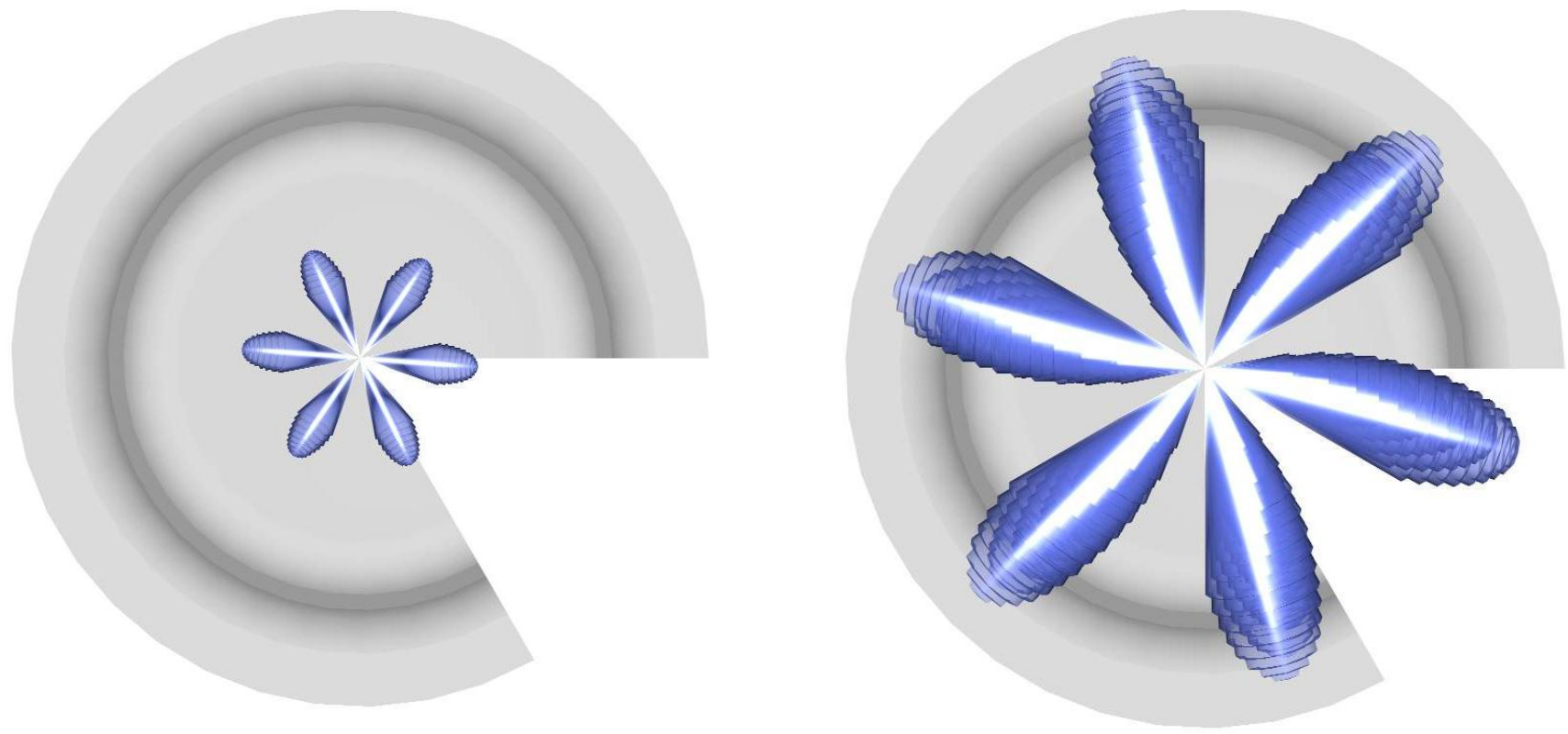

Figure 61 Evolution of the fuel spray in high swirl $(\omega=3) ; \alpha=18.75^{\circ} \mathrm{CAD}$ BTDC;

$P_{i n j}=110 \mathrm{MPa} ; t=0.1 \mathrm{~ms}$ at left and $t=0.7 \mathrm{~ms}$ at right; Top view 
From Figures 60 and 61 can be seen the sprays' development for various crank angles and injection pressure of $110 \mathrm{MPa}$. It is obvious that after $0.7 \mathrm{~ms}$ the spray impinges into the wall of combustion chamber and it seems that this injection pressure is excessive to the engine. A pressure of $80 \mathrm{MPa}$ was found to be optimum for the engine.

\section{Fuel Properties Influence on the Spray Development-Preliminary Analysis}

Using this mathematical model a comparison of biofuel spray development has been attempted with an analysis of the effects of varying fuel properties. The influence of biodiesel density on Sauter Mean Diameter was calculated and is presented in Figure 62. From the results is apparent that introducing biodiesel with higher density that ULSD2 in the mixture will slightly decrease the SMD but at the same time will increase substantially because the viscosity increase and that is the main factor of influence Figure 63.
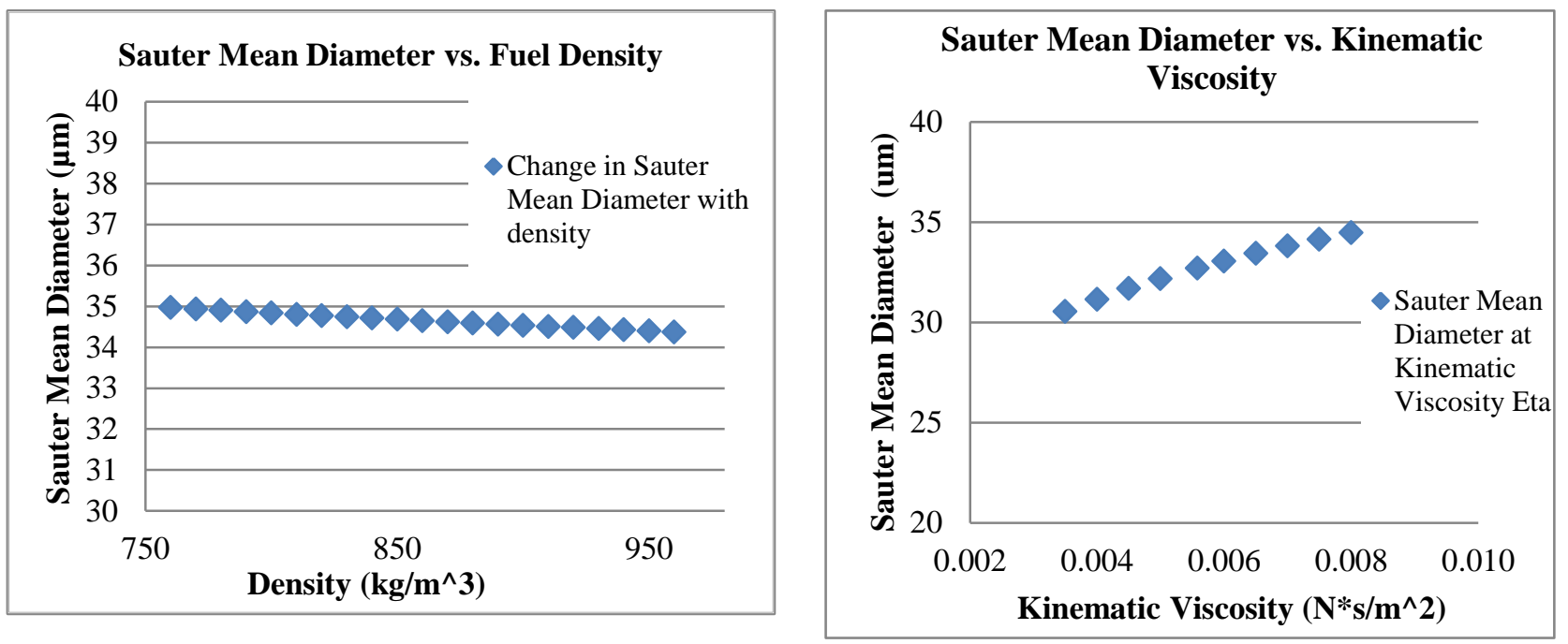

Figures 62-63 The effect of fuel density and viscosity on SMD
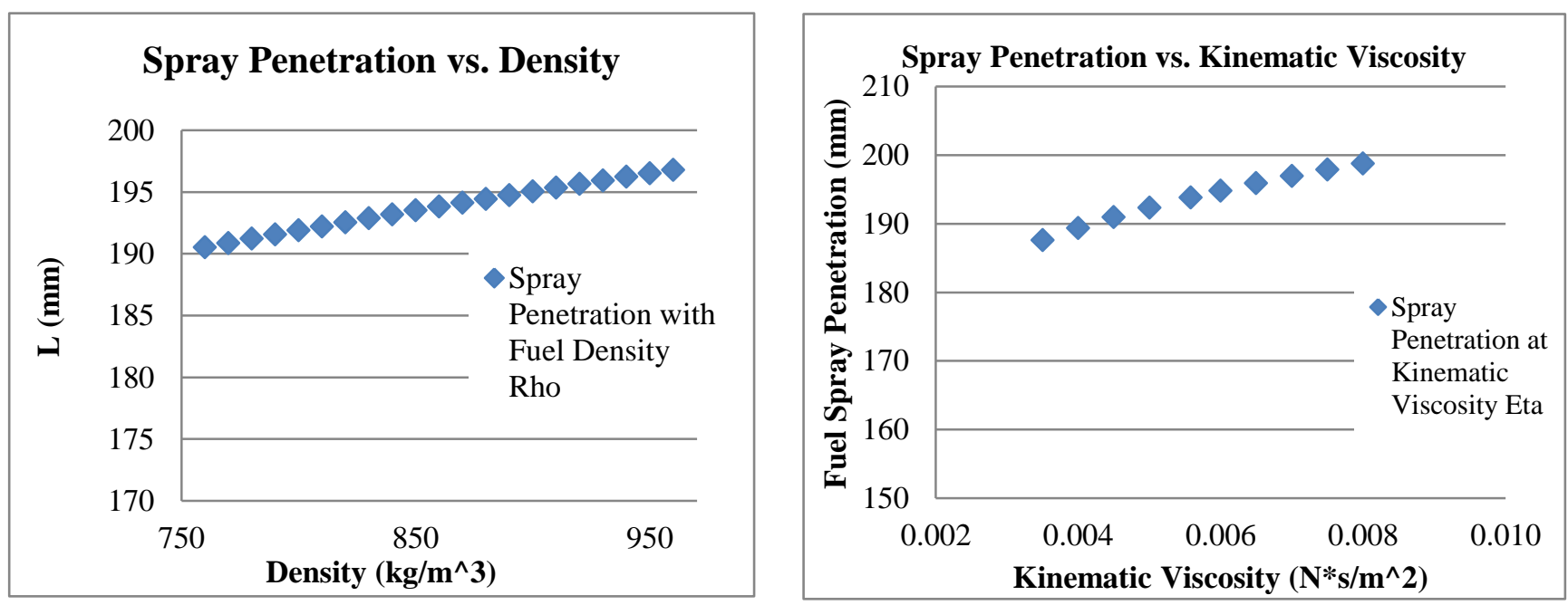

Figures 64-65 Spray penetration function of density and viscosity 
From Figure 64 is visible an increase of penetration with increased density of biodiesel and that combined with increased viscosity will add even more penetration, seen in Figure 65.
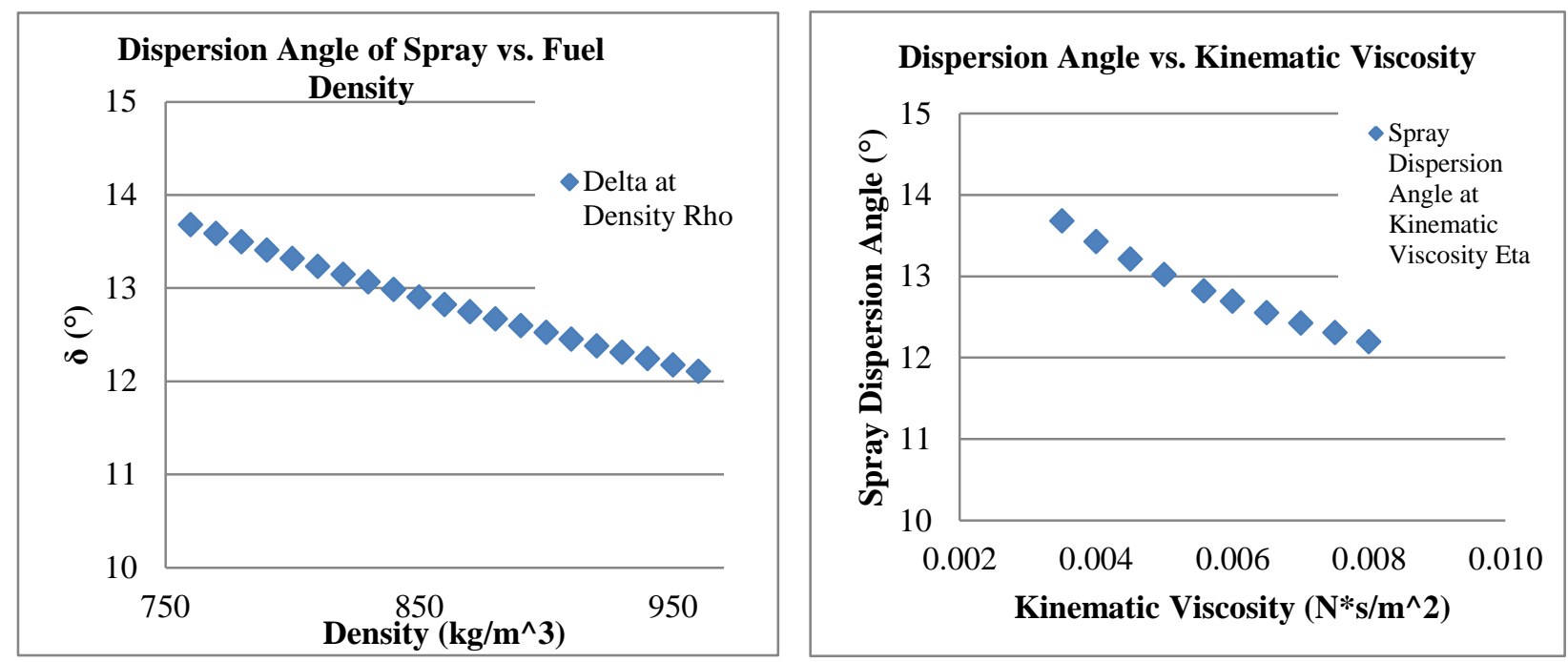

Figures 66-67 Dispersion angle function of density and viscosity

From Figure 66 is visible that the dispersion angle will increase with increased biodiesel blends and the spray will entrain less air and the same trend is valid for increased spray viscosity as presented in Fig. 67.

\section{SUMMARY}

The development of the laboratory and the acquisition of new state of the art equipment was extremely beneficial for research in GSU. New students recruiting were possible and research extended also to the undergraduate level.

In terms of results there are conclusions to be drawn both on the engine side, fueling strategies and also on the fuels behavior.

The dynamic viscosity of the test fuels increased with larger peanut FAME and methyl oleate content in the fuel blends, but was still within the acceptable ASTMD6751-09 standard for biodiesel.

The ignition delay was diminished with the injection of Peanuts FAME and the combustion had two distinctive phases very well defined: a premixed phase and a diffusion combustion for both fuels. The FAME could maintain the maximum combustion pressure and matched the ULSD\#2 efficiency. For the DI engine at the idling speed, has been found a low maximum combustion temperature of $1550 \mathrm{~K}$ that if would be sustained at higher loads could develop into a Low Temperature Region.

That may be obtained with a new injection and fuelling strategy may that could be obtained by a combination of single-shot direct biodiesel injection and low pressure sequential alcohol port injection. LTC could be achieved for low to medium loads when combined with PCCI.

Emissions of soot and NOx for FAME were better practically at all loads compared with ULSD but CO, $\mathrm{HC}$, NMHC and aldehydes have been slightly higher. $\mathrm{CO}_{2}$ emissions matched those of diesel and having the same trends. For the IDI engine the injection and combustion of peanut FAME-ULSD and methyl oleate-ULSD blends from $20 \%$ to $50 \%$ (wt./wt.) was investigated. The new alternative fuels had no ignition problems and combustion promoters such as intake manifold heating, pilot injection, or increased swirl ratios were not required to achieve a satisfactory performance. The IDI engine investigated had the premixed and diffusion combustion phases combined and exhibited an ignition delay that was roughly the same for peanut FAME and methyl Oleate showing a remarkable fuel tolerance. The heat release showed a favorable development for high speed diesel engine operation, with combined premixed and diffusion 
combustion phases and the fuels had similar combustion characters with ULSD\#2. The engine's mechanical efficiency with peanut FAME and methyl oleate showed roughly the same values as ULSD at 6.2 imep with the mechanical efficiency being $77 \%$, while the engine overall efficiency obtained with P20-P50 and O20-O50 was at decreased from ULSD 36\% to $29 \%$. Contributing factors to this phenomenon are an increased mean indicated pressure influenced by increased mechanical work absorbed by the injection pump, and the interaction of the chemical characteristics of the FAME combustion.

The emissions data showed favorable results with an insignificant increase for the tested FAME blends when compared to ULSD. The study showed that methyl oleate displays similar characteristics with that of a Peanut FAME and ULSD. This suggests that methyl oleate could be used as a surrogate for FAME combustion modeling and supporting its use in indirect injection compression ignition engines and contributing to the attainment of biofuel usage goals.

The simulation work comprised both engines thermodynamics and also spray development for the DI case. The spray could be characterized and qualitative knowledge gained.

Task A5.0 Annual research report Reports and other deliverables have been provided in accordance with the Federal Assistance Reporting Checklist following the instructions included therein.

Task A5.1 Deliverable reports

Periodic and final reports have been submitted in accordance with the "Federal Assistance Reporting Checklist" and the instructions accompanying the checklist. In addition to these documents, the following will also have been submitted to the appointed Government Project Officer: Summary of accomplishments and project work report prepared for inclusion in the annual programmatic progress report. The report has submitted per requirements of the Federal Assistance Reporting Checklist. Scientific/technical reports (including conference papers/proceedings, journal articles) based on the research are submitted according to DOE rules.

\section{NOMENCLATURE}

A $\quad$ constant in Annand model [-]

ARHR Apparent Rate of Heat Release

$A_{p} \quad$ Cross Sectional Area of the plunger $\left[\mathrm{mm}^{2}\right]$

APU Auxiliary Power Unit

BMEP Brake Mean Effective Pressure [bar]

BSFC Brake Specific Fuel Consumption [g/kW-hr]

CAD Crank Angle Degree [deg.]

$\mathrm{Cm}$ piston average speed $[\mathrm{m} / \mathrm{s}]$

CN Cetane Number

D engine bore [m]

EGR Exhaust Gas Recirculation

FAME Fatty Acid Methyl Esters

$\mathrm{N} \quad$ engine speed [rpm]

NOP Nozzle Opening Pressure [MPa]

NREL National Renewable Energy Laboratory

$\mathrm{P}$ pressure [Pa]

Po Initial System Pressure [MPa]

$\mathrm{R} \quad$ in cylinder Reynolds number [-]

$\mathrm{S} \quad$ engine stroke [m]

TA cylinder volume-averaged instantaneous gas temperature [K]

TDC Top Dead Center

$\theta \quad$ Theta [CAD]

Tw cylinder wall average temperature [K]

ULSD Ultra Low Sulfur Diesel

$\mathrm{V} \quad$ Piston Displacement Volume $\left[\mathrm{m}^{3}\right]$

$\mathrm{V}_{\mathrm{f}} \quad$ Volume of Compressed Fuel $\left[\mathrm{mm}^{3}\right]$ 


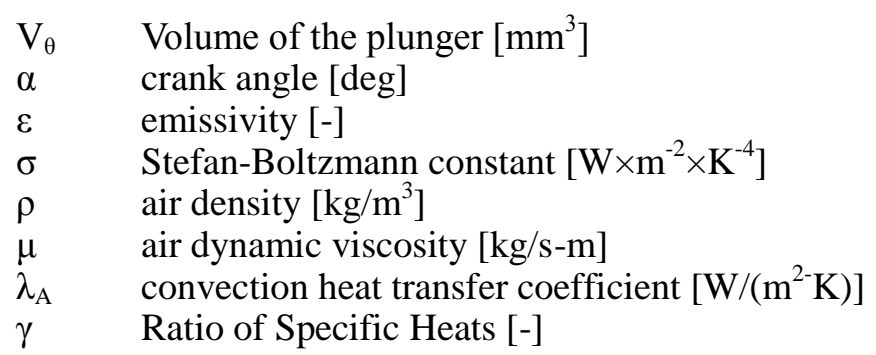

\section{REFERENCES}

1. Bamgboye, A., and Hansen, A., 2008, "Prediction of Cetane Number of Biodiesel Fuel from the Fatty Acid Methyl Ester (FAME) Composition," International Agrophysics.

2. Soloiu, V., Nelson, D., \& Covington, A., 2011 "Investigations of a Fatty Acid Methyl Ester from Poultry Fat in a Triple Vortex Separate Combustion Chamber Diesel Engine Stage OneCombustion Investigations," SAE Paper No. 2011-01-1188

3. Soloiu, V., Lewis, J., Convington, A., Vlcek, B., and Schmidt, N., 2011, "The Influence of Peanut Fatty Acid Methyl Ester Blends on Combustion in an Indirect Injection Diesel Engine," ICEF2011-60053, Internal Combustion Engine Division Fall Technical Conference, ASME, Morgantown, VA.

4. Soloiu, V., Lewis, J., Covington, A., Nelson, D., and Schmidt, N., 2011, "Oleic Methyl Ester Investigations in an Indirect Injection Diesel Engine; Stage One: Combustion Investigations", $S A E$ Int. J. Fuels Lubr, Vol. 4, Issue 1

5. Soloiu, V., Yoshihara, Y, Nishiwaki K, Nakanishi, Y., Combustion and Emissions Characteristics of a Polypropylene Blended Diesel Fuel in a Direct Injection Compression Engine, Proceedings of the ASME 2010 Internal Combustion Engine Division Fall Technical Conference ICEF2010 2010 San Antonio, TX, 2010.

6. McCarthy, P., Rasul, M.G., Moazzem, S., 2011, "Analysis and Comparison of Performance and Emissions of an Internal Combustion Engine Fuelled with Petroleum Diesel and Different Biodiesels, Elsevier, Fuel.

7. Tat, M., E., and Van Gerpen, J., H., 2003, "Measurement of Biodiesel Speed of Sound and its Impact on Injection Timing," Technical Report No. 4, NREL, Iowa State University, Ames, Iowa.

8. Annand, W. J. D., Ma, T. H., Instantaneous Heat Transfer Rates to the Cylinder Head Surface of a Small Compression-Ignition Engine. Proc. Instn. Mech. Engrs, vol. 185, pp. 976-987, 1971.

9. Specification for Biodiesel (B100), 2008, ASTM D6751-09.

10. Graboski, M., S., McCormick, R., L., Alleman, T., L., Herring, A., M., 1999, "Effect of Biodiesel Composition in NOx and PM Emissions from a DDC Series 60 ENGINE", NREL, CSM Contract No. ACG-8-17106-02.

11. Borman, G., Nishiwaki, K., 1987, “Internal-Combustion Engine Heat Transfer”, Prog Energy Combust Sci, Vol. 13 1-46.

12. Grünwald, B., Kuhnt, H., Gheorghiu, V.: Investigation on the fuel distribution in direct injection Diesel engine combustion chambers and its influence on soot emission (JET2), CI MACCongress , 1991, Florenz, Italien (CIMAC 1991)

13. Kuo, T.-W.. Evaluation of a phenomenological spray-combustion model for two open-chamber diesel engines. Proceedings of the International fuels and lubricants meeting and exposition(1987)

14. Kamimoto, T, Yokota, H, \& kobayashi, H. (1987). Effect of high pressure injection on soot formation processes in a rapid compression machine to simulate diesel flames. Proceedings of the International off-highway \& powerplant congress and exposition

15. Hiroyasu, H, Arai. A.; Structures of Fuel Sprays in Diesel Engines SAE Paper No. 900475 (1990)

16. Apostolescu, N, Chiriac, R, Moses, E, \& Radu, BA General fuel spray model for the mixing process analysis in combustion engines. Revue Roumaine des sciences techniques. Electrotechnique et énergétique, 32(2), 235-244. . (1987). 